\title{
EL NUEVO MAPA DE LAS AGENCIAS EUROPEAS DEL ESPACIO DE LIBERTAD, SEGURIDAD Y JUSTICIA MONTSERRAT PI LLORENS ${ }^{1}$ \\ montserrat.pi@uab.cat
}

\author{
Cómo citar/Citation \\ Pi Llorens, M. (2017). \\ El nuevo mapa de las agencias europeas del Espacio \\ de Libertad, Seguridad y Justicia. \\ Revista de Derecho Comunitario Europeo, 56, 77-117. \\ doi: https://doi.org/10.18042/cepc/rdce.56.03
}

\section{Resumen}

El mapa de las agencias del Espacio de Libertad, Seguridad y Justicia se encuentra inmerso en un proceso de cambios que ha aportado ya novedades notables y que dista mucho de estar cerrado. El nuevo marco jurídico-político que ha supuesto la reforma de Lisboa — con la desaparición del tercer pilar y la adopción por parte de las instituciones europeas de un planteamiento común para las agencias descentralizadas - ha exigido una adaptación de las agencias del Espacio de Libertad, Seguridad y Justicia, tradicionalmente caracterizadas por un marcado sesgo intergubernamental y por sus múltiples particularidades. En el artículo se analizan las principales cuestiones planteadas por dicho conjunto de reformas, que han incidido tanto en el ámbito material de actuación de estas agencias, reforzando de manera notable sus capacidades, como en su diseño y estructura, haciendo especial hincapié en el incremento de su control político y jurisdiccional.

\section{Palabras clave}

Agencias europeas; Espacio de Libertad, Seguridad y Justicia; planteamiento común para las agencias descentralizadas; EUROPOL; EUROJUST; FRONTEX; EASO; EULISA; FRA; OEDT.

1 Profesora titular de Derecho Internacional Público, Universitat Autònoma de Barcelona. 


\title{
THE NEW MAP OF THE EUROPEAN AGENCIES IN THE AREA OF FREEDOM, SECURITY AND JUSTICE
}

\begin{abstract}
The map of the AFSJ agencies is engaged into a process of changes that has already brought remarkable new features and that is still on going. The new legal and political framework of the Lisbon reform, which prompted the abolishment of the third pillar and the adoption of a Common Approach for decentralized agencies by the European institutions, has required an adaptation of the AFSJ agencies, which have been traditionally characterized by an intergovernmental nature and multiple peculiarities. This article analyses the main issues raised by the set of changes established in the Lisbon Treaty, which have influenced both the substantive scope of these agencies - notably strengthening their capacities - as well as their design and structure, with a special emphasis on its political and jurisdictional control.
\end{abstract}

\section{Keywords}

European agencies; Area of Freedom, Security and Justice; Common approach for decentralized agencies; EUROPOL; EUROJUST; FRONTEX; EASO; EULISA; FRA; EMCDDA.

\section{LE NOUVEAU CADRE DES AGENCES EUROPÉENNES DE L'ESPACE DE LIBERTÉ, DE SÉCURITÉ ET DE JUSTICE}

\section{Résumé}

Les agences européennes de l'Espace de Liberté, de Sécurité et de Justice font l'objet d'un processus de réforme qui a déjà signifié des nouveautés importantes et qui n'est pas encore fini. Les agences de l'Espace de Liberté, de Sécurité et de Justice ont dû s'adapter au nouveau cadre juridique et politique du Traité de Lisbonne, avec la suppression du troisième pilier, et de l'Approche Commune concernant les agences décentralisées adoptée par les institutions européennes. L'article examine les questions posées par ces réformes, notamment en ce qui concerne le renforcement de ses compétences et la redéfinition de ses structures, avec un plus grand control politique et juridictionnel.

\section{Mots clés}

Agences européennes, Espace de Liberté, de Sécurité et de Justice; Approche Commune concernant les agences décentralisées; EUROPOL; EUROJUST; FRONTEX; EASO; EULISA; FRA; EMCDDA. 


\section{SUMARIO}

I. INTRODUCCIÓN: UN NUEVO MARCO JURÍDICO-POLÍTICO PARA LAS AGENCIAS EUROPEAS. II. LAS AGENCIAS COMO ACTORES DE INTEGRACIÓN Y DE IMPULSO DEL ELSJ: 1. Definiendo las agencias del ELSJ. 2. El fortalecimiento de las capacidades de las agencias. 3. La potenciación de la transversalidad y la cooperación. III. UNA NUEVA GOBERNANZA PARA LAS AGENCIAS DEL ELSJ: 1. Reequilibrios en los órganos de gobierno de las agencias. 2. Hacia un mayor control democrático. 3. El control jurisdiccional. IV. CONSIDERACIONES FINALES.

\section{INTRODUCCIÓN: UN NUEVO MARCO JURÍDICO-POLÍTICO PARA LAS AGENCIAS EUROPEAS}

El mapa de las agencias del Espacio de Libertad, Seguridad y Justicia (ELSJ) ha sufrido importantes cambios en los últimos años con la creación de nuevos organismos — como la Oficina Europea de Apoyo al Asilo (EASO) en 2010 o la Agencia Europea para la Gestión Operativa de Sistemas Informáticos de Gran Magnitud (EULISA) en 2011-y la revisión de otros con el objetivo de reforzar sus capacidades — como la Agencia Europea para la Gestión de la Cooperación Operativa en las Fronteras Exteriores (FRONTEX) en 2011-. Este proceso de reformas está lejos de poder considerarse cerrado: en el último año se han adoptado sendos nuevos reglamentos para la Agencia de la Unión Europea para la Formación Policial (CEPOL) y la Agencia de la Unión Europea para la Cooperación Policial (EUROPOL), se ha creado la nueva Guardia Europea de Fronteras y Costas y se están negociando las propuestas de reforma para la nueva Agencia Europea de Cooperación en Materia de Justicia Penal (EUROJUST) y la nueva Agencia de Asilo de la Unión Europea.

Las razones que explican esta dinámica son variadas ${ }^{2}$. En el plano político, los recientes acontecimientos vinculados a la crisis de los refugiados han situado a las agencias en el corazón de la agenda de las instituciones europeas y los Estados

2 Para un análisis general sobre los factores que influyen en el desarrollo de las agencias del ELSJ, véase C. KAUNERT, S. LÉONARD, J. D. OCCHIPINTI (eds.), Justice and Home Affairs Agencies in the European Union, Routledge, London and New York, 2015, pp. 3-6. 
miembros ${ }^{3}$. En el plano jurídico, tanto la entrada en vigor del Tratado de Lisboa como la adopción por parte del Parlamento Europeo (PE), el Consejo y la Comisión de un Planteamiento Común sobre las agencias descentralizadas ${ }^{4}$ han aportado nuevas reglas que han afectado directamente a las agencias del ELSJ.

Dicho Planteamiento Común tiene como objetivo ofrecer criterios generales para la creación y el diseño de las agencias, y hacer hincapié en su gobernanza, responsabilidad y control. Se busca encuadrar dichos organismos en un marco institucional más homogéneo y estandarizado. A pesar de que no constituye un acto jurídico con carácter vinculante ${ }^{5}$, manifiesta la voluntad de las instituciones de sentar unos principios a los que deben responder todas las agencias europeas, por lo que pueden tener un especial impacto en las agencias del ELSJ, cuyo carácter específico ha sido ampliamente subrayado por la doctrina, que, en algunos casos, ha llegado incluso a excluir a algunas de ellas de la categoría de agencias ${ }^{6}$.

En cuanto al Tratado de Lisboa, las principales novedades que afectan a las agencias del ELSJ provienen de la desaparición de la estructura de la Unión Europea (UE) en pilares. Como es sabido, la cooperación penal pasa a estar regulada en el Tratado de Funcionamiento de la Unión Europea (TFUE) en el

3 Recuérdese, como muestra, que en septiembre de 2015 los jefes de Estado o de Gobierno de los Estados miembros pidieron que se reforzaran los controles en las fronteras, entre otros medios incrementando las capacidades de FRONTEX, EASO y EUROPOL (Declaración tras la Reunión Informal de los Jefes de Estado o de Gobierno, 23 de septiembre de 2015, doc. 673/15).

4 Declaración Común del PE, el Consejo de la UE y la Comisión Europea sobre las agencias Descentralizadas, 19 de julio de 2012, que incluye en anexo un Planteamiento Común, disponible en http://europa.eu/european-union/sites/europaeu/files/docs/body/joint_statement_and_common_approach_2012_es.pdf (consultado por última vez el 19.11.2016).

5 La falta de ambición del documento, tanto por lo que respecta a su naturaleza jurídica como a su contenido, ha sido objeto de críticas por parte de la doctrina. Véase, en este sentido, E. BERNARD, "Accord sur les agences européennes : la montagne accouche d'une souris», Revue du Droit de l'Union européenne, núm. 3, 2012, pp. 399-446; M. CHAMON, «Les agences de l'Union européenne: origines, état des lieux et défis», CDE, núm. 1, 2015, pp. 293-318, p. 312.

6 Chiti, por ejemplo, las sitúa aparte, y las denomina «organismos transnacionales»; E. CHITI, «Existe-t-il un modèle d'Agence de l'Union Européenne?», en J. MOLINIER (dir.), Les Agences de l'Union européenne, Bruylant, Bruxelles, 2011, pp. 49-74, p. 57. En el mismo sentido, Vírgala, por considerar que «[...] aunque formalmente pertenecientes a la administración europea, desde el punto de vista operativo dependen de los Estados, ejecutores originarios y genuinos de dicha cooperación»; E. VÍRGALA, Las agencias reguladoras de la UE, Comares, Granada, 2011, p. 42. 
marco del ELSJ junto con las demás políticas, con todas las implicaciones que supone un funcionamiento que obedece más a la lógica de la integración que a la de cooperación que presidía el tercer pilar, a pesar de que subsisten algunas especificidades ${ }^{7}$. Estos cambios pueden agruparse, también para las agencias, en dos grandes ámbitos: el competencial y el institucional. Desde un punto de vista competencial, la reforma de Lisboa ha reforzado las capacidades de la UE, lo que ha incidido claramente en algunas agencias, ampliando su potencial y abriendo la puerta a una transferencia de poderes ejecutivos, como la creación de un sistema europeo de guardias de fronteras o de una fiscalía europea.

En cuanto a la dimensión institucional, el aspecto más destacado es la mayor implicación del PE, la Comisión y el Tribunal de Justicia de la Unión Europea (TJUE). La desaparición de la lógica de pilares ha implicado la apuesta por el procedimiento legislativo ordinario para la adopción de los instrumentos jurídicos que fijen las opciones esenciales en este ámbito, también para la regulación de las agencias. En el caso de EUROJUST y EUROPOL, esto supone una novedad importante, pues hasta Lisboa las decisiones que rigieron dichas agencias fueron adoptadas por el Consejo con una mera consulta al PE, a iniciativa de la Comisión en el caso de EUROPOL ${ }^{8}$, y de un grupo de Estados miembros en el caso de EUROJUST ${ }^{9}$. Además de esta mejora, en cuanto al papel del $\mathrm{PE}$ en la regulación de las agencias, la reforma de Lisboa ha apostado también por un mayor control democrático de estas. En concreto, las nuevas bases jurídicas de EUROJUST y EUROPOL obligan al legislador europeo a incluir en su reglamentación modalidades de control por parte del PE y los parlamentos nacionales. Por lo que respecta al TJUE, han desaparecido las limitaciones que el antiguo tercer pilar establecía a su

7 Por ejemplo, en materia de iniciativa legislativa o de control judicial. Sobre este tema, véase S. CARRERA, F. GEYER, «El Tratado de Lisboa y un Espacio de Libertad, Seguridad y Justicia: Excepcionalismo y Fragmentación en la Unión Europea», $R D C E$, núm. 29, 2008, pp. 133-162; J. MARTÍN PÉREZ DE NANCLARES, «El espacio de libertad, seguridad y justicia en el Tratado de Lisboa», Revista de las Cortes Generales, núm. 70-72, 2007, pp. 85-126; y S. PEERS, EU Justice and Home Affairs Law, Oxford University Press, Oxford, 2012.

8 La participación de la Comisión en la regulación de EUROPOL fue una de las novedades de la reforma que sufrió en 2009 dicha agencia, que previamente había sido creada y regulada mediante un convenio entre los Estados miembros en virtud del tercer pilar. La reforma de 2009 implicó refundar EUROPOL mediante la Decisión 2009/371/JAI del Consejo, de 6 de abril de 2009, por la que se crea la Oficina Europea de Policía (DO L 121, de 15 de mayo de 2009, p. 37).

9 Decisión 2009/426/JAI del Consejo, de 16 de diciembre de 2008, por la que se refuerza EUROJUST (DO L 138, de 4 de junio de 2009, p. 14). 
jurisdicción ${ }^{10}$, por lo que las decisiones del ámbito de la cooperación penal quedan sometidas al régimen común del contencioso europeo. Ello - unido a las referencias expresas a los actos adoptados por los organismos de la UE que se han introducido en la regulación de algunas vías de recurso- puede significar un control judicial más claro en relación tanto con los actos de creación de las agencias del ELSJ como con sus actuaciones.

En este contexto, el presente artículo pretende examinar las principales novedades que ha supuesto la adaptación de las agencias del ELSJ a este nuevo marco jurídico-político. Obviamente, no todas las agencias se verán afectadas en la misma medida, por lo que lo que se ofrecerá, a continuación, es una panorámica general y no un análisis detallado agencia por agencia. Dicha panorámica se ha estructurado en torno a dos grandes grupos de cuestiones, en consonancia con las principales novedades aportadas en este ámbito por el Tratado de Lisboa aquí comentadas: el impulso material otorgado a los objetivos del ELSJ — que en el caso de las agencias significa un mayor protagonismo y unas mayores capacidades (II) — y los cambios institucionales - que pueden suponer un nuevo modelo de gobernanza y de estructura para algunas de ellas, haciendo especial hincapié en el refuerzo de su control, tanto político como jurisdiccional (III)_- Este examen nos permitirá valorar, en unas consideraciones finales (IV), las principales tendencias y potencialidades que se desprenden de este proceso de reformas y los retos aún pendientes.

\section{LAS AGENCIAS COMO ACTORES DE INTEGRACIÓN Y DE IMPULSO DEL ELSJ}

\section{DEFINIENDO LAS AGENCIAS DEL ELSJ}

Las agencias vinculadas al ELSJ ${ }^{11}$ responden a la definición de las denominadas agencias reguladoras o descentralizadas ${ }^{12}$ que se caracterizarían por

10 Con la excepción prevista en el art. 276 del TFUE en materia de orden público y salvaguardia de la seguridad interior.

11 Las agencias del ELSJ son EUROPOL, CEPOL, EUROJUST, FRONTEX, EASO, EULISA. Sin embargo, en el presente artículo se incluyen también referencias a la Agencia de los Derechos Fundamentales (FRA), el Instituto Europeo de la Igualdad de Género (EIGE) y el Observatorio Europeo para las Drogas y las Toxicomanías (OEDT), que, aunque no desarrollan sus actividades exclusivamente en este ámbito, sí contribuyen de forma relevante a la consecución de los objetivos del ELSJ. Este enfoque amplio es acorde con la práctica institucional de la UE, como se expondrá a lo largo de los diferentes apartados.

12 El término reguladoras ha sido criticado por parte de la doctrina por confuso, teniendo en cuenta la gran diversidad de tareas que realizan (por ejemplo, VÍRGALA, op. 
su carácter formalmente autónomo, con personalidad jurídica propia, y su contribución activa al desarrollo de las políticas de la $\mathrm{UE}^{13}$. Más en concreto, en 2005, la Comisión proponía la siguiente fórmula para definirlas: «Entidad jurídica autónoma creada por la autoridad legislativa para participar en la regulación de un sector a escala europea y en la ejecución de una política comunitaria determinada $»^{14}$, una definición que no se aleja mucho de las que pueden encontrarse en diferentes propuestas doctrinales, que en general subrayan como rasgos esenciales su personalidad jurídica propia, su creación a partir de un acto de derecho derivado y su carácter de organismos permanentes de derecho público europeo ${ }^{15}$.

Más allá de estas características genéricas, la diversidad de estructura, tamaño y poderes entre las agencias en general y las del ELSJ en particular es tal que no existe una tipología consensuada de ellas. En este sentido, son varios los criterios barajados tanto por la propia Comisión como por la doctrina para sistematizarlas: temporal, estructural, funcional o instrumental. Estos últimos son los más generalizados, ya que atienden a las distintas actividades llevadas a cabo por las agencias, que van desde la adopción de decisiones jurídicas, la asistencia científica y técnica, la coordinación de actividades operativas o la recogida y difusión de informaciones ${ }^{16}$. Dado que una misma agencia puede

cit., p. 46, supra nota 6). En los últimos años la Comisión parece haber optado por el término descentralizadas, que también ha sido objeto de críticas por considerar que enmascara el hecho de que se trate de organismos europeos, que lo único que tienen descentralizado son la sede y la composición de los consejos de administración (CHAMON, op. cit., p. 302, supra nota 5).

13 Ambos elementos permiten distinguirlas de las agencias ejecutivas, caracterizadas por sus tareas estrictamente de gestión para asistir a la Comisión en la aplicación de programas comunitarios y el sometimiento a su control, como se desprende de su regulación en el Reglamento 58/2003/CE del Consejo, de 19 de diciembre de 2002, por el que se establece el estatuto de las agencias ejecutivas encargadas de determinadas tareas de gestión de los programas comunitarios (DO L 11, de 16 de enero de 2003, p. 1).

14 Comisión Europea, Proyecto de Acuerdo Interinstitucional sobre el encuadramiento de las agencias reguladoras europeas, COM (2005) 59 final, de 25 de febrero de 2005.

15 Véase, entre otros, E. VOS, «European Agencies and the Composite EU Executive», en M. EVERSON; C. MONDA; E. VOS (eds.), European Agencies in Between Institutions and Member States, The Netherlands, Wolters Kluwer, 2014, pp. 11-47, p. 19.

16 Se pueden encontrar este tipo de clasificaciones en diversos autores, como VÍRGALA, op. cit., supra nota 5, pp. 58 y ss. 
cumplir distintas funciones, parece acertado centrarse en una sistematización de funciones y de instrumentos más que de agencias ${ }^{17}$.

En el caso específico de las agencias del ELSJ, estas no solo presentan denominaciones, tareas y estructuras muy diversas entre ellas, sino también en relación con el resto de las agencias europeas. No hay que olvidar que algunas operan en ámbitos muy ligados al núcleo de la soberanía estatal, como la cooperación penal, la inmigración o el asilo, en los que la UE ha adquirido competencias de manera relativamente reciente y que resultan especialmente sensibles a causa de su impacto en la opinión pública, como los recientes acontecimientos en la crisis de los refugiados han puesto claramente de manifiesto. En este contexto, la creación de agencias ha resultado una vía atractiva para los Estados, ya que funcionan más como estructuras de cooperación y coordinación que como organismos dotados de poderes ejecutivos operacionales ${ }^{18}$. Ello es coherente con una posición de los Estados dispuesta a reforzar la cooperación, pero reticente a la adopción de normas comunes y al refuerzo de los poderes de la Comisión o del $\mathrm{PE}^{19}$, por lo que el proceso de agencificación de este sector puede considerarse difícilmente evitable. En este sentido, la creación de algunas de las agencias del ELSJ obedece a motivos diferentes a los de la mayoría de las agencias descen-

17 Representativo de ello es la posición del Tribunal de Cuentas Europeo, que en su Informe especial de 2008 renuncia a clasificarlas y opta por realizar una diferenciación de sus competencias. En concreto, distingue siete tipos: recogida y difusión de informaciones, organización de seminarios y competencias, creación de redes y coordinación de acciones nacionales y comunitarias, soporte científico y técnico, concepción de estudios y formulación de consejos y recomendaciones, observación y seguimiento de políticas sectoriales, formulación de dictámenes y expedición de certificados (Tribunal de Cuentas Europeo, Informe especial núm. 5/2008, Agencias de la Unión Europea: obtener resultados, Anexo 1, disponible en http://www.eca.europa.eu/Lists/ECADocuments/SR08_05/SR08_05_ES.PDF [consultado por última vez el 10.11.2016]). En el ámbito doctrinal, una opción parecida encontramos en CHAMON, op. cit., p. 297, supra nota 5.

18 En el desarrollo de las actividades operativas el papel de las agencias es de coordinación, es decir, dependen de los Estados, puesto que son ellos los auténticos protagonistas de las operaciones.

19 Monar considera un tanto exagerado hablar de una estrategia defensiva por parte del Consejo, pero afirma que algunas agencias del ELSJ traducen un equilibrio que favorece a los Estados en detrimento de Comisión y Parlamento. J. MONAR, «The Institutional Framework of the AFSJ: Specific Challenges and Dynamics of Change», en J. MONAR (ed.), The Institutional Dimension of the European Union's Area of Freedom, Security and Justice, College of Europe Studies, núm. 11, Peter Lang, Bruselas, 2010, pp. 21- 49, p. 43. 
tralizadas. Aquí no se trataba de aligerar el trabajo de la Comisión —o de proporcionar a esta un expertise técnico y altamente especializado en campos que así lo requieren-, sino de incrementar o fortalecer la cooperación entre los Estados para hacer frente a retos de carácter transnacional ${ }^{20}$. Es por ello que estas agencias prestan una gran asistencia a los Estados más que a las instituciones europeas - lo cual es también uno de sus rasgos específicos que explica la vinculación de algunas de ellas mucho más estrecha con el Consejo que con la Comisión ${ }^{21}$ - y no disponen de un poder regulatorio que sí tienen otras agencias descentralizadas. La intervención en acciones de carácter operativo es también un elemento singular, puesto que se trata de actividades que no ejecuta ninguna otra agencia europea. De hecho, ni siquiera es propio de todas las agencias del ELSJ, siendo característica de FRONTEX ${ }^{22}$, EUROPOL y EUROJUST, pero no de la FRA, el Instituto Europeo de la Igualdad de Género (EIGE) o el OEDT, que pueden ser calificadas como agencias de información, ni tampoco de CEPOL ni de EULISA, que responden a un modelo de agencias de gestión ${ }^{23}$.

Esta apuesta de los Estados, compartida por la Comisión, a favor del recurso a agencias con funciones a la carta en el campo del ELSJ, se ha reforzado claramente en el Tratado de Lisboa y en su desarrollo, lo que ha tenido como consecuencia reformas que tienden a fortalecer sus poderes operativos y ejecutivos y a potenciar la coordinación y cooperación entre ellas.

20 M. BUSUIOC, European Agencies. Law and Practices of Accountability, Oxford University Press, Oxford, 2013, p. 29.

21 J. RIJPMA, «Institutions and Agencies: Government and Governance after Lisbon», en D. ACOSTA ARZARAZO; C. C. MURPHY (eds.), EU Security and Justice Law after Lisbon and Stockholm, Hart Publishing, Oxford, 2014, pp. 54-76, p. 63.

22 FRONTEX ha sido descrita como una agencia dual, que desarrolla tanto tareas de cooperación operativa como las más clásicas de una agencia descentralizada de asistencia técnica en la implementación de una política común. J. RIJPMA, «Hybrid Agencification in the Area of Freedom, Security and Justice and Its Inherent Tensions: The Case of FRONTEX», en M. BUSUIOC et al. (eds.), The Agency Phenomenon in the European Union: Emergence, Institutionalisation and Everyday Decision-Making, Manchester University Press, Manchester, 2012, pp. 84-102.

23 Las primeras se dedican básicamente a la recogida, tratamiento, difusión de información y elaboración de estudios. Las segundas gestionan un servicio específico. Para dicha categorización véase M. JORDANA, «El control de la Comisión y el Consejo a las agencias del Espacio de Libertad, Seguridad y Justicia», en C. BLASI; M. ILLAMOLA (coords.), El control de las agencias del Espacio de Libertad, Seguridad y Justicia: contrapeso necesario a su autonomia, Marcial Pons, Madrid, 2016, pp. 21-46, p. 24. 


\section{EL FORTALECIMIENTO DE LAS CAPACIDADES DE LAS AGENCIAS}

EUROJUST y EUROPOL siguen siendo las dos únicas agencias del ELSJ que se mencionan expresamente en el TFUE que, tras la reforma de Lisboa, les dedica una base jurídica propia (los arts. 85 y 88 ) en la que se establecen sus funciones y competencias reforzando y clarificando su mandato ${ }^{24}$. Este debe concretarse en un acto adoptado por las instituciones europeas siguiendo el procedimiento legislativo ordinario, un acto que adoptará la forma de reglamento. El paso de la unanimidad a la mayoría cualificada en el Consejo que implica el procedimiento legislativo ordinario puede considerarse el reconocimiento de una cierta consolidación de dichas agencias ${ }^{25}$. Además, el TFUE incluye una nueva base jurídica (el art. 86) que permite crear una Fiscalía Europea.

A partir de estas bases, la Comisión ha ejercido su poder de iniciativa legislativa y ha presentado sus propuestas de reforma para adaptar los mandatos de dichas agencias al nuevo marco jurídico ofrecido por los Tratados. En el campo de la cooperación policial, la propuesta inicial implicaba un cambio sustancial en el mapa de las agencias, puesto que planteaba la fusión entre CEPOL y EUROPOL ${ }^{26}$. Dicha posición topó con un rechazo absoluto por parte de los Estados miembros y del $\mathrm{PE}^{27}$, lo que llevó a la Comisión a presentar una nueva propuesta para reformar la norma de base de $\mathrm{CEPOL}^{28}$, que ha dado lugar a la aprobación de su nuevo Reglamento en noviembre de $2015^{29}$. Tam-

24 En el antiguo tercer pilar del TUE, ambas agencias no merecían una disposición propia, sino que se incluían como un instrumento en la descripción de los objetivos y de las actuaciones de la UE en materia de cooperación penal. Sobre las potencialidades que la reforma aporta en el caso de EUROJUST, véase MONAR, op. cit., pp. 67-84, supra nota 19.

JORDANA, op. cit., p. 28, supra nota 23.

26 La Comisión, basándose en el planteamiento común para las agencias descentralizadas ya mencionado, en el que se afirma que en casos en que se solapen las tareas de distintas agencias, en que puedan contemplarse sinergias o en que pueda obtenerse una mayor eficiencia debe considerarse su fusión (Declaración común, loc. cit., p. 1 del anexo, supra nota 3), consideró que este era el caso para dichas agencias y contempló la desaparición de CEPOL, COM (2013) 173 final, de 27 de marzo de 2013.

27 Según consta en las enmiendas formuladas en su Dictamen en primera lectura, doc. P7_TA (2014)0121.

28 Propuesta de Reglamento del Parlamento Europeo y del Consejo por el que se crea una Agencia de la Unión Europea para la formación en funciones coercitivas (CEPOL), COM (2014) 465 final, de 30 de septiembre de 2014.

29 Reglamento (UE) 2015/2219 del Parlamento Europeo y del Consejo, de 25 de noviembre de 2015, sobre la Agencia de la Unión Europea para la formación policial 
bién se ha aprobado en 2016 la nueva reglamentación de EUROPOL, que empezará aplicarse a partir del 1 de mayo de $2017^{30}$. El objetivo general de la reforma es asignar a la agencia nuevas responsabilidades, de forma que pueda prestar un apoyo más amplio a los Estados miembros y se constituya como un centro de inteligencia de referencia. Entre otras medidas, la propuesta refuerza la obligación de los Estados de suministrar datos a la agencia y permite a la agencia acceder a las bases de datos de las autoridades policiales nacionales. También prevé la posibilidad de que EUROPOL inicie una investigación criminal y refuerza su participación en los Equipos Conjuntos de Investigación. Se prevé, asimismo, que EUROPOL pueda desarrollar centros para la lucha contra formas específicas de delincuencia, en particular en materia de terrorismo. Su nuevo mandato, pues, apunta a una evolución en la que la agencia añade a su papel tradicional de coordinación nuevas capacidades de iniciativa y de decisión ${ }^{31}$.

En lo que concierne a EUROJUST, dos son las propuestas que están sobre la mesa de las instituciones europeas, presentadas en la misma fecha como parte de un único paquete: la reforma del Reglamento base de la agencia y la creación de una Fiscalía Europea ${ }^{32}$. Entre los objetivos de la reforma de EUROJUST, figura mejorar su eficacia operativa mediante una definición homogénea del estatus y la competencia de los miembros nacionales ${ }^{33}$. También se contempla la relación de EUROJUST con la futura Fiscalía Europea. Esta última tendría una competencia centrada exclusivamente en el fraude contra los intereses financieros de la UE. Se configuraría, en la propuesta de la Comisión, como una oficina independiente y descentralizada, compuesta

(CEPOL) y por el que se sustituye y deroga la Decisión 2005/681/JAI del Consejo (DO L 319, de 4 de diciembre de 2015, p. 1).

30 Reglamento (UE) 2016/794 del Parlamento Europeo y del Consejo, de 11 de mayo de 2016, relativo a la Agencia de la Unión Europea para la cooperación policial (EUROPOL) (DO L 135, de 24 de mayo de 2016, p. 53).

31 En palabras de Blasi, «Se puede concluir que EUROPOL adquiere con el nuevo Reglamento ciertos poderes regulatorios». C. BLASI, «El Reglamento europeo de EUROPOL: un nuevo marco jurídico para el intercambio de datos policiales en la UE», Revista General de Derecho Europeo, núm. 40, 2016, p. 207.

32 Propuesta de Reglamento del Consejo relativo a la creación de la Fiscalía Europea, COM (2013) 534 final de 17 de julio de 2013. Propuesta de Reglamento del Parlamento Europeo y del Consejo sobre la Agencia Europea de Cooperación en materia de Justicia Penal (EUROJUST), COM (2013) 535 final de 17 de julio de 2013.

33 Para un análisis general sobre la propuesta de reforma de EUROJUST, véase A. WEYEMBERGH, «An Overall Analysis of the Proposal for a Regulation on EUROJUST», Eucrim, núm. 4, 2013, pp. 127-131. 
por un fiscal europeo y fiscales delegados europeos en los Estados miembros. Trabajaría en asociación con EUROJUST, con quien compartiría recursos. La propuesta de la Comisión en relación con la Fiscalía Europea ha encontrado serios obstáculos entre los Estados miembros. La negociación política dista de estar cerrada ${ }^{34}$ y el hecho de que ambas propuestas se estén negociando conjuntamente conlleva que la reforma de EUROJUST se encuentre igualmente paralizada ${ }^{35}$.

El resto de agencias que operan en el ELSJ no aparecen mencionadas expresamente en el TFUE, pero la reforma de Lisboa ha supuesto reforzar las competencias de la UE en sus ámbitos de actuación, lo que ha permitido la utilización de las nuevas bases jurídicas materiales del Tratado para reforzar los poderes de dichas agencias. Este es el caso en particular de la política de asilo en relación con EASO y de FRONTEX.

En el caso de EASO, tras apenas cinco años de funcionamiento de la agencia $^{36}$, la Comisión ha presentado ya una nueva propuesta para dotarla de mayores capacidades y medios, dentro de un paquete de medidas tendentes

34 Ante la constatación de la imposibilidad de alcanzar la unanimidad requerida, dieciséis estados han comunicado oficialmente su intención de iniciar una cooperación reforzada en este ámbito, http://www.consilium.europa.eu/es/press/press-releases/2017/04/03-eppo/ (consultado por última vez el 13 de abril de 2017).

35 Es preciso recordar que el TFUE prevé que la Fiscalía se creará mediante un procedimiento legislativo especial, que requiere unanimidad en el seno del Consejo y aprobación previa del PE, a diferencia del reglamento que regula EUROJUST, para el que el TFUE prevé un procedimiento legislativo ordinario.

36 EASO fue creada en 2010 mediante el Reglamento (UE) 439/2010 del Parlamento Europeo y del Consejo, de 19 de mayo de 2010, por el que se crea una Oficina Europea de Apoyo al Asilo (DO L 132, de 29 de mayo de 2010, p.11). Sobre los trabajos de dicha agencia, véase F. COMTE, «A New Agency Is Born in the European Union. The European Asylum Support Office», European Journal of Migration and Law, vol. 12, 2010, pp. 373-405; E. ZAPATER, "La dimensión exterior de la Oficina Europea de Apoyo al Asilo (EASO): una agencia esencial en la implementación del Sistema Europeo Común de Asilo (SECA)», en M. PI; E. ZAPATER (coords.), La dimensión exterior de las agencias del espacio de libertad, seguridad y justicia, Marcial Pons, Madrid, 2014, pp. 183-200; M. GARLICK, «Practical Cooperation and the First Years of the EASO", en Searching for Solidarity in EU Asylum and Border Policies, A Collection of Short Papers following the Odysseus Network's First Annual Policy Conference, 26-27, February 2016, pp. 10-12, disponible en http://odysseus-network.eu/wp-content/uploads/2015/09/Searching-for-Solidarity-Short-Papers.pdf (consultado por última vez el 16.1.2017). 
a reformar el Sistema Europeo Común de Asilo (SECA) ${ }^{37}$. Para enfatizar la relevancia de los cambios, la Comisión propone una nueva denominación: Agencia de Asilo de la Unión Europea. Se trata básicamente de ofrecer a la agencia un nuevo marco legal que le permita ser menos dependiente de los Estados miembros y dotarse de los instrumentos necesarios para llevar a cabo su mandato reforzado. Como novedad importante destaca la propuesta de la Comisión de que la agencia pueda elaborar estándares sobre la implementación de la normativa europea en materia de asilo e indicadores que permitan controlar el grado de cumplimiento de estos. Asimismo, la propuesta prevé un mecanismo de control sobre la aplicación del SECA por parte de los Estados ${ }^{38}$, que se concretará en informes que pueden ir acompañados de recomendaciones a los Estados. En caso de que los Estados no las sigan y ello constituya un riesgo para el buen funcionamiento del sistema, el tema pasaría a manos de la Comisión, que podría llegar a adoptar una Decisión que regule las medidas que deben ser adoptadas por el Estado ${ }^{39}$. En el campo operativo, se refuerza la capacidad de la agencia de organizar equipos de apoyo a los Estados a partir de sus demandas o a iniciativa propia. En caso de que el ofrecimiento de la agencia no sea aceptado y ello genere una situación de riesgo para el sistema, se prevé de nuevo la intervención de la Comisión ${ }^{40}$. Aunque resulta prematuro realizar valoraciones - puesto que la propuesta de la Comisión se encuentra en fase de estudio y negociación en el seno del Consejo y del Parlamento, junto con el resto de propuestas de modificación del SECA, y de buen seguro sufrirá cambios y limitaciones-, hay que destacar la atribución de nuevas capacidades cuasi reguladoras a la agencia, y un papel de supervisión de los Estados que resulta absolutamente novedoso.

Por lo que respecta a FRONTEX, como es sabido, ya en 2011 se procedió a una amplia reforma de su reglamento de creación para reforzar sus fun-

37 Comisión Europea, Propuesta de Reglamento del Parlamento Europeo y del Consejo relativo a la Agencia de Asilo de la Unión Europea y por el que se deroga el Reglamento (UE) 439/2010, COM (2016) 271 final, de 4 de mayo de 2016.

38 El art. 13 de la propuesta (loc. cit., supra nota 37) especifica que la supervisión versará, entre otros, sobre la aplicación por parte de los Estados del sistema de Dublín, las condiciones de acogida, los procedimientos de asilo, la naturaleza y la calidad de la protección otorgada y los sistemas de acogida y asilo (recursos, infraestructuras, capacidad de las autoridades de asilo, incluido el sistema judicial), así como el cumplimiento por los Estados de las normas operativas en materia de asilo.

39 Arts. 16 y 22 de la propuesta de Reglamento presentada por la Comisión, loc. cit., supra nota 37.

40

Idem. 
ciones $^{41}$. Se buscaba ampliar las capacidades operativas de la agencia y mejorar los recursos técnicos disponibles, pero también se insistió en la necesidad de que todas sus actuaciones respeten íntegramente los derechos fundamentales y los derechos de los refugiados y solicitantes de asilo, en particular la prohibición de devolución ${ }^{42}$. FRONTEX adquirió también un nuevo protagonismo a raíz de la adopción del Sistema Europeo de Vigilancia de Fronteras (EUROSUR) en 2013, que representa un marco permanente de cooperación entre las autoridades competentes de los Estados miembros y la agencia ${ }^{43}$.

La afluencia sin precedentes de inmigrantes que se está registrando en Europa en los últimos meses y que está cuestionando todo el sistema Schengen ha puesto de nuevo a FRONTEX y sus capacidades en el punto de mira. Para hacer frente a sus actuales limitaciones, dentro de un paquete de medidas difundidas por la Comisión el 15 de diciembre de 2015, se presentó la propuesta de crear una Guardia Europea de Fronteras y Costas ${ }^{44}$. Dicha propuesta ha sido negociada en un tiempo récord ${ }^{45}$, y el nuevo Reglamento fue

41 Reglamento (UE) 1168/2011 del Parlamento Europeo y del Consejo de 25 de octubre de 2011, que modifica el Reglamento (CE) 2007/2004 por el que se crea una Agencia Europea para la Gestión de la Cooperación Operativa en las Fronteras Exteriores de los Estados miembros de la UE (DO L 304, de 22 de noviembre de 2011, p. 1).

42 Sobre esta reforma, véase M. URREA, «El control de fronteras exteriores como instrumento para la seguridad: una aproximación al nuevo marco jurídico de FRONTEX», Revista del Instituto Español de Estudios Estratégicos, núm. 0, 2012, pp. 153-172. Sobre las obligaciones que FRONTEX tiene que respetar en sus operaciones marítimas, véase S. MARINAI, "The Interception and Rescue at Sea of Asylum Aeekers in the Light of the New EU Legal Framework», RDCE, núm. 55, 2016, pp. 901-939.

43 Su objetivo es facilitar el intercambio de información en tiempo cuasi real, para poner en común la información policial, estrechando la cooperación a nivel nacional y europeo, Reglamento (UE) 1052/2013 del Parlamento Europeo y del Consejo de 22 de octubre de 2013, por el que se crea un Sistema Europeo de Vigilancia de Fronteras (EUROSUR) (DO L 295, de 6 de noviembre de 2013, p. 11).

44 Propuesta de Reglamento del Parlamento Europeo y del Consejo sobre la Guardia Europea de Fronteras y Costas, COM (2015) 671 final de 15 de diciembre de 2015. Para un análisis de las principales novedades, véase J. RIJPMA, The Proposal for a European Border and Coast Guard: Evolution or Revolution in External Border Management?, Parlamento Europeo, Estudio para la comisión LIBE, 2016; D. FERNÁNDEZ ROJO, «Creación de una Guardia de Fronteras y Costas: breve análisis de la Propuesta de Reglamento de la Comisión de 15 de diciembre de 2015», European Papers, vol. 1, núm. 1, 2016, pp. 203-212.

45 La prioridad que las instituciones han otorgado a la mejora del control de fronteras mediante esta propuesta contrasta con la dificultad para adoptar otro tipo de respuestas a la crisis migratoria, como, por ejemplo, la reforma del sistema europeo común 
definitivamente adoptado el 14 de septiembre de $2016^{46}$. La nueva Guardia Europea engloba a una nueva Agencia Europea de la Guardia de Fronteras y Costas, formada a partir de FRONTEX con funciones adicionales, y a las autoridades responsables de la gestión de fronteras en los Estados miembros, que seguirán ejerciendo la gestión cotidiana de las fronteras exteriores. $\mathrm{Su}$ objetivo es establecer una estrategia operativa para la gestión integrada de las fronteras y ayudar a los Estados a implementarla. Nótese que será la agencia la que establecerá dicha estrategia en el ámbito europeo, mientras que los Estados, por su parte, elaborarán estrategias en el ámbito nacional, que deberán ser conformes con la adoptada por la agencia ${ }^{47}$. Se atribuye, así, una capacidad cuasirreguladora a la agencia, al tiempo que se mejora su capacidad operativa, pues dispondrá de una reserva rápida de guardias de fronteras (formada por al menos 1500 guardas, con una contribución obligatoria de los Estados miembros) y más equipos técnicos, y tendrá un papel mayor en materia de retorno, a pesar de no haber prosperado la propuesta inicial de la Comisión de crear en el seno de la agencia una Oficina de Retorno ${ }^{48}$. También se enfatiza su labor de análisis y seguimiento de riesgos, para lo que los Estados estarán obligados a suministrar información, lo que potenciará su contribución al campo de la

de asilo o las consecuencias del principio de solidaridad, lo que pone de manifiesto el enfoque securitario imperante. En este mismo sentido, tampoco se ha activado la Directiva relativa a las normas mínimas para la concesión de protección temporal en caso de afluencia masiva de personas desplazadas, y a medidas de fomento de un esfuerzo equitativo entre los Estados miembros para acoger a dichas personas y asumir las consecuencias de su acogida, a pesar de que ha habido sobradas ocasiones que hubiesen justificado poner en marcha esta respuesta común (Directiva 2001/55/ CE del Consejo, de 20 de julio de 2001, DO L 212, de 7 de agosto de 2001, p.12). Para una crítica sobre lo que puede aportar la nueva agencia a los retos que plantea la actual situación de las fronteras europeas véase S. CARRERA, L. DEN HERTOG, A European Border and Coast Guard: What's in a name?, CEPS Paper in Liberty and Security in Europe, núm. 88, 2016; T. SPIJKERBOER, "Minimalist Reflections on Europe, Refugees and Law», European Papers, vol. 1, núm. 2, 2016, pp. 533-558. Reglamento (UE) 2016/1624 del Parlamento Europeo y del Consejo de 14 de septiembre de 2016 sobre la Guardia Europea de Fronteras y Costas (DO L 251, de 16 de septiembre de 2016, p. 1).

47 Art. 3 del Reglamento (UE) 2016/1624, loc. cit., supra nota 46. Sobre la incidencia de la denominada crisis de los refugiados en el modelo europeo de fronteras, véase A. DEL VALLE, «Los refugiados, las fronteras exteriores y la evolución del concepto de frontera internacional», $R D C E$, núm. 55, 2016, pp. 759-777.

Arts. 27 a 33 del Reglamento (UE) 2016/1624, loc. cit., supra nota 46. 
inteligencia y el procesamiento de datos ${ }^{49}$. El refuerzo de FRONTEX se proyecta también hacia al exterior mediante la coordinación de la cooperación operativa entre los Estados miembros y Estados terceros, la participación en operaciones conjuntas en territorios de Estados terceros y el despliegue de funcionarios de enlace ${ }^{50}$.

La propuesta más atrevida lanzada inicialmente para permitir la intervención de la agencia en casos graves y urgentes, incluso sin el acuerdo del Estado afectado, a partir de una decisión de la Comisión, ha sido objeto de cambios por el legislador, de modo que la decisión de intervenir en un Estado que no es capaz de gestionar sus fronteras queda en manos del Consejo por mayoría cualificada, a propuesta de la Comisión ${ }^{51}$. En la misma línea, se asigna a la agencia una nueva función de seguimiento y supervisión (la denominada evaluación de vulnerabilidad) que le permitirá evaluar la capacidad de los Estados de controlar sus fronteras y dirigirles, si es preciso, recomendaciones sobre medidas que deberían adoptarse dentro de un determinado plazo. En este proceso, resulta especialmente interesante e innovadora la previsión de que, en caso de no cumplir con dichas recomendaciones, el director de la agencia elevará la cuestión al consejo de administración, que podrá dirigir una decisión al Estado implicado en la que indique qué medidas debe aplicar y en qué plazo, una decisión que será vinculante ${ }^{52}$. En caso de que también esta decisión sea incumplida por el Estado, el asunto pasará a manos del Consejo de la UE, que podrá tomar las medidas oportunas mediante una decisión de ejecución. Este conjunto de atribuciones dibuja una nueva agencia cuyas capacidades se han visto notablemente ampliadas. Sin embargo, estamos aún

49 Art. 11 del Reglamento (UE) 2016/1624, loc. cit., nota 46. Sin embargo, también aquí la propuesta de la Comisión fue objeto de modificaciones, puesto que no se mantiene en el Reglamento aprobado la creación de un centro de análisis y seguimiento de riesgos en el seno de la agencia.

50 Arts. 54 y 55 del Reglamento (UE) 2016/1624, loc. cit., supra nota 46.

51 Art. 19 del Reglamento (UE) 2016/1624, loc. cit., nota 46. Una parte de la doctrina expresó sus dudas acerca de si la propuesta de la Comisión respetaba las competencias que los Tratados reservan a los Estados en materia de seguridad interior y orden público. En este sentido, véase S. PEERS, «The Reform of FRONTEX: Saving Schengen at Refugees' Expense?», EU Law Analysis, diciembre 2015, disponible en http:// eulawanalysis.blogspot.com.es/2015/12/the-reform-of-frontex-saving-schengen.html (consultado por última vez el 19.11.2016). Al respecto no debe olvidarse que estamos ante un mecanismo excepcional y temporal, que tiene su origen en una incapacidad del Estado de cumplir sus obligaciones en cuanto al control de fronteras, por lo que no parece que estemos ante una invasión de competencias estatales.

52 Art. 13 del Reglamento (UE) 2016/1624, loc. cit., supra nota 46. 
lejos de un organismo dotado de poderes ejecutivos independientes. Carrera y Den Hertog afirman en este sentido que estamos ante un FRONTEX+ más que ante una auténtica guardia europea de fronteras y costas ${ }^{53}$.

Por último, no hay que olvidar que, tras la entrada en vigor del Tratado de Lisboa, el mapa de las agencias del ELSJ se ha visto también ampliado con la creación de EULISA, cuyo objetivo es gestionar los sistemas informáticos de gran magnitud ${ }^{54}$. En la exposición de motivos de su Reglamento de base, se enfatiza la voluntad de crear sinergias que permitan realizar economías de escala, crear una masa crítica y garantizar la mayor tasa posible de utilización de capital y recursos humanos. Inicialmente, la agencia era responsable del Sistema de Información de Schengen de Segunda Generación (SIS II) y el Sistema de Información de Visados (VIS), a los que, posteriormente, se ha añadido también la base de datos europea de solicitantes de asilo (EURODAC) y en el futuro se pueden añadir otras bases de datos. Se trata de una agencia de carácter marcadamente técnico y de gestión, que puede contribuir a aportar eficacia y rigurosidad y a prestar asistencia técnica a las demás agencias del ELSJ ${ }^{55}$.

Así pues, la entrada en vigor del Tratado de Lisboa y su desarrollo legislativo por las instituciones europeas han convertido a las agencias en unos actores clave para la consecución de los objetivos del ELSJ y, por tanto, del proceso de integración en este ámbito. Articulando e incrementando la cooperación entre Estados en materias que siguen siendo de su competencia, no cabe duda de que las agencias con una dimensión operativa contribuyen de manera destacada a la europeización de sectores sensiblemente ligados a la soberanía estatal.

53 CARRERA, DEN HERTOG, op. cit., p. 1 y p. 16, supra nota 45. El carácter poco ambicioso de la nueva regulación y el carácter equívoco de la denominación, en la medida en que no se crea un auténtico cuerpo europeo de guardias, ha sido subrayado también por P. DE BRUYCKER, «The European Border and Coast Guard: A New Model Built on an Old Logic», Europeanpaper, vol. 1, núm. 2, 2016, pp. 559-569, p. 568. De este mismo autor puede verse «Solidarity as a Sovereignty-Reducing Penalty for Failing to Meet Responsibility in the European Border an Coast Guard", en Searching for Solidarity in EU Asylum and Border Policies, op. cit., pp. 13-14, supra nota 36. Por su parte, Rijpma subraya el potencial de las nuevas capacidades de la agencia, que considera que se convierte en un primus inter pares en materia de control de fronteras (RIJPMA, op. cit., p. 28, supra nota 44).

54 Reglamento (UE) 1077/2011 del Parlamento Europeo y del Consejo, de 25 de octubre de 2011, por el que se establece una agencia europea para la gestión operativa de sistemas informáticos de gran magnitud en el ELSJ (DO L 286, de 1 de noviembre de 2011, p. 1).

55 Véase M. ILLAMOLA, «EU-LISA, nuevo modelo de gestión operativa de bases de datos de la UE», Revista CIDOB d'Afers Internacionals, núm. 111, 2015, pp. 105-126. 


\section{LA POTENCIACIÓN DE LA TRANSVERSALIDAD Y LA COOPERACIÓN}

La consolidación del ELSJ como un objetivo de la UE en la reforma de Lisboa y su regulación en un único Título del TFUE, gracias a la desaparición de los pilares, ha propiciado que se imponga un enfoque más global y transversal para su desarrollo. En el plano de las agencias, ello significa, por un lado, poner en primer plano la necesidad de articular vías de cooperación entre ellas y, por otro, asociar a otras agencias que, a pesar de que sirven a otras políticas de la UE y se han creado a partir de otras disposiciones de los Tratados, contribuyen también desde un punto de vista material a desarrollar los objetivos del ELSJ, lo cual comporta su inclusión en el nuevo mapa de las agencias del ELSJ. Se trata esencialmente de la $\mathrm{FRA}^{56}$ y del $\mathrm{EIGE}^{57}$, vinculadas a la dimensión «justicia» del ELS ${ }^{58}$, y del OEDT, que aporta su expertise en la lucha contra el narcotráfico, uno de los principales ámbitos delictivos de especial gravedad y con una dimensión transfronteriza, cuya represión forma parte de los objetivos de la cooperación judicial y policial penal regulada en el ELSJ ${ }^{59}$.

56 Creada mediante el Reglamento (CE) 168/2007 del Consejo, de 15 de febrero de 2007 (DO L 53 de 22 de febrero de 2007, p. 1). La protección de los derechos fundamentales está en el centro de la construcción del ELSJ, como exige el art. 67 TFUE, y por ello la FRA está llamada a tener una contribución relevante en este ámbito, más intensa si cabe que en otras áreas de actuación de la UE. A pesar de que no hay ninguna propuesta sobre la mesa y que no parece que ésta sea una prioridad de la actual Comisión, se ha suscitado la necesidad de revisar su reglamento de base. El propio consejo de administración de la agencia ha presentado unas Recomendaciones que instan a las instituciones europeas a lisbonizar la agencia y modificar su reglamento para adaptarlo al nuevo marco jurídico de la UE, disponibles en http://fra.europa.eu/ sites/default/files/fra-management-board-recommendations-external-evaluation_0. pdf (consultado por última vez el 22.11.2016).

57 Creado por el Reglamento (CE) 1922/2006 del Parlamento Europeo y del Consejo de 20 de diciembre de 2006 (DO L 403, de 30 de diciembre de 2006, p. 9). En relación con EIGE, cabe preguntarse si no nos encontramos ante uno de los casos recogidos en el Planteamiento Común de solapamiento de tareas o de oportunidad de sinergias y mayor eficiencia, que aconsejaría una fusión con la FRA. Aunque creemos que existen sólidos argumentos en este sentido, no hay que olvidar que las razones que rodean la creación de una agencia y su posible desaparición son eminentemente políticas, como recientemente ha puesto de manifiesto el caso de CEPOL antes comentado. RIJPMA, op. cit., p. 63, supra nota 21.

59 Regulado por el Reglamento (CE) 1920/2006 del Parlamento Europeo y del Consejo, de 12 de diciembre de 2006 (DO L 376, de 27 de diciembre de 2006, p. 1). Sobre la contribución del OEDT al ELSJ, véase C. JIMÉNEZ, A. AYUSO, «El Observatorio 
Por lo que se refiere a la cooperación entre agencias, su necesidad se ha puesto de manifiesto en los documentos políticos adoptados por las instituciones europeas para el desarrollo de los objetivos del ELSJ. Tanto en el Programa de Estocolmo y su respectivo Plan de Acción ${ }^{60}$, que guiaron las prioridades estratégicas en este ámbito en el período 2009-2014, como en las Estrategias adoptadas por el Consejo Europeo en junio de $2014^{61}$, que han supuesto su continuación, encontramos referencias expresas al papel relevante que están llamadas a desempeñar todas ellas, en el que destaca la voluntad de avanzar hacia una mayor coherencia y mejora de su coordinación, bajo la supervisión del Consejo ${ }^{62}$. Por su parte, la Estrategia de Seguridad Interior, adoptada por el Consejo en febrero de 2010 y aprobada por el Consejo Europeo en el mes siguiente ${ }^{63}$, así como la agenda presentada por la Comisión para su desarrollo ${ }^{64}$, hacen especial énfasis en la necesidad de adoptar un enfoque global y en la cooperación de las diferentes autoridades implicadas, tanto el ámbito europeo como entre los Estados. Con este propósito se ha adoptado la metodología de los denominados ciclos de actuación, que intentan «hacer frente a las principales amenazas delictivas de forma coherente y metódica” ${ }^{65}$. Cada ciclo de actuación, previsto para cuatro años ${ }^{66}$, consta de cuatro fases ${ }^{67}$, en las que el

Europeo de las Drogas y las Toxicomanías», en PI, ZAPATER, op. cit., pp. 163-182, supra nota 36.

Programa de Estocolmo: una Europa abierta y segura que sirva y proteja al ciudadano, adoptado por el Consejo Europeo en diciembre de 2009 (DO C115, de 4 de mayo de 2010, p.1), y Plan de Acción por el que se aplica el Programa de Estocolmo, COM (2010) 171 final, de 20 de abril de 2010.

61 Conclusiones del Consejo Europeo de 26 y 27 de julio de 2014, Doc. EUCO 79/14.

62 Programa de Estocolmo, loc. cit., p. 6, supra nota 60.

63 Estrategia de Seguridad interior para la Unión Europea: Hacia un modelo europeo de seguridad, Documento del Consejo 5842/2/2010.

64 Comisión Europea, La Estrategia de Seguridad Interior en acción: cinco medidas para una Europa más segura, COM (2010) 673 final, de 22 de noviembre de 2011.

65 Conclusiones del Consejo sobre el establecimiento y aplicación de un ciclo de actuación de la UE contra la delincuencia organizada y las formas graves de delincuencia internacional, doc. $15358 / 10$ de 25 de octubre de 2010. El ciclo de actuación vigente abarca el período 2014-2017: Conclusiones del Consejo sobre la determinación de las prioridades de la UE para la lucha contra la delincuencia grave y organizada entre 2014 y 2017 , doc. 12095/13.

67 Elaboración de una estrategia sobre la base de una evaluación de amenazas (denominada SOCTA); formulación de una política, determinando prioridades y planes estratégicos; ejecución de planes de acción operativos en consonancia con las prioridades definidas; evaluación del ciclo de actuación que pueda servir de base para el siguiente ciclo. 
Comité Permanente de Cooperación Operativa en materia de Seguridad Interior (COSI), vinculado al Consejo ${ }^{68}$, desempeña un papel central. Pues bien, en todo este proceso participan de forma activa diversas agencias del ELSJ, que trabajan conjuntamente. El documento SOCTA, que establece un mapa de riesgos y es la base sobre la que se definen las políticas, lo elabora EUROPOL ${ }^{69}$ a partir de datos y contribuciones de los Estados miembros, pero también de EUROJUST, FRONTEX y el OEDT ${ }^{70}$. Las agencias también intervienen en la ejecución de las prioridades elaborando, junto con los expertos de los Estados miembros, los planes de acción operativos relativos a las acciones relacionadas con sus mandatos. Por último, CEPOL desempeña también un papel activo de difusión y de formación dirigida específicamente a las prioridades y acciones acordadas ${ }^{71}$.

Otra manifestación cada vez más relevante de la cooperación entre agencias la constituye su actuación en los denominados hotspots o puntos críticos. Esta medida, contemplada en la Agenda Europea de Migración adoptada en $2015^{72}$, pretende facilitar la intervención rápida e integrada de FRONTEX, EASO y EUROPOL en el territorio de los Estados que sufran una presión migratoria excepcional o desproporcionada. Se trata de intensificar la cooperación que dichas agencias ya venían desarrollando en el

68 Se ha señalado que este papel creciente del COSI significa fortalecer la influencia del Consejo, a expensas de una visión más supranacional y de una mayor influencia de la Comisión, RIJPMA, op. cit., p. 86, supra nota 22.

69 Sobre la relevancia de EUROPOL en este ámbito, véase H. CARRAPIÇO, F. TRAUNER, «Europol and Its Influence on EU Policy-Making on Organized Crime: Analyzing Governance Dynamics and Opportunities», en KAUNERT; LÉONARD; OCCHIPINTI, op. cit., pp. 84-99, supra nota 2.

70 Ello no significa atribuirles una papel decisorio ni nuevas funciones más allá de su mandato, aunque como señalan Busuioc y Curtin: «[...] las líneas divisorias entre el asesoramiento político y la verdadera formulación de políticas se vuelven difusas en la práctica, especialmente teniendo en cuenta el estrecho vínculo existente entre la evaluación de amenazas, la determinación de prioridades políticas y las consiguientes opciones políticas», M. BUSUIOC, D. CURTIN, La Estrategia de Seguridad Interior de la UE, el ciclo de actuación de la UE y la función de las agencias (ELSJ), Parlamento Europeo, Estudio para la Comisión LIBE, 2011, p. 7.

71 El ciclo de actuación ha tenido hasta ahora un enfoque esencialmente policial, con un gran protagonismo de EUROPOL, pero el Consejo ha invitado a la participación en la ejecución del mismo a todas las agencias del ELSJ (agencias JAI en la terminología del Consejo) y podría fomentarse la vertiente «justicia», incorporando a FRA. En este sentido, véase BUSUIOC, CURTIN, op. cit., p. 16, supra nota 70.

72 Comisión Europea, Una Agenda Europea de Migración, COM (2015) 240 final, de 13 de mayo de 2015. 
control de las fronteras, la gestión de las solicitudes de asilo y la lucha contra el tráfico y la trata de personas, previendo una actuación conjunta sobre el terreno. Las tareas de las agencias en los hotspots se coordinan en una oficina (la European Union Regional Task Force), que constituye también el enlace de sus actuaciones con las autoridades nacionales. A pesar de que el despliegue de dicho enfoque en la práctica ha resultado dificultoso hasta ahora ${ }^{73}$, no cabe duda de que está llamado a desempeñar un importante papel en el futuro, como lo pone de manifiesto el Reglamento de la nueva Agencia de la Guardia de Fronteras y Costas, que introduce su regulación y encomienda a dicha agencia la coordinación y gestión de todos los equipos de apoyo que se desplieguen en los hotspots ${ }^{74}$. La cooperación entre las agencias en este marco puede resultar positiva siempre que el funcionamiento de dichos centros sea transparente y respetuoso con los derechos fundamentales. A la vista de las críticas que los primeros hotspots puestos en marcha han recibido y que cuestionan precisamente dichas cuestiones ${ }^{75}$, sería deseable la adopción de un instrumento legal que estableciera un marco jurídico común ${ }^{76}$.

Por último, todas las agencias del ELSJ desarrollan una importante actividad de coordinación y cooperación entre ellas, prevista en sus reglamentaciones

73 Para una buena descripción de su desarrollo, así como un análisis de los problemas prácticos y legales que suscitan, véase D. FERNÁNDEZ ROJO, «Hotspot Approach: Cooperación y control de FRONTEX, EASO y EUROPOL», en BLASI; ILLAMOLA, op. cit., pp. 105-121, supra nota 23; A. DRAKOPOULOU, «Hotspots: The Case of Greece», en Searchingfor Solidarity in EU Asylum and Border Policies, op. cit., pp. 19-22, supra nota 36; F. TRAUNER, "Asylum Policy: the EU's 'crises' and the looming policy regime failure», Journal of European Integration, vol. 38, núm. 3, 2016, pp. 311-335.

74 Para una visión crítica de esta regulación, véase RIJPMA, op. cit., p. 19, supra nota 44.

75 Véase L. ANSEMS DE VRIES, S. CARRERA, E. GUILD, Documenting the Migration Crisis in the Mediterranean. Spaces of Transit, Migration Management and Migrant Agency, CEPS Paper in Liberty and Security in Europe, núm. 94, Septembre 2016, disponible en www.ceps.eu (consultado por última vez el 16.1.2017); M. PICHOU, «Reception or Detention Centres? The Detention of Migrants and the New 'hotspot' Approach in the Light of the European Convention on Human Rights", Critical Quarterly for Legislation and Law, núm. 2, 2016, pp. 114-131, disponible en https:// papers.ssrn.com/sol3/papers.cfm?abstract_id=2730654 (consultado por última vez el 16.1.2017).

76 Esta propuesta se recoge en D. NEVILLE, S. SY, A. RIGON, On the Frontline: The Hotspots Approach to Managing Migration, Parlamento Europeo, Estudio para la Comisión LIBE, 2016. 
de base, que se ha traducido en la celebración de acuerdos de trabajo ${ }^{77}$, además de una serie de prácticas y relaciones informales en el día a día de sus tareas ${ }^{78}$. Esta relación bilateral se complementa con una coordinación multilateral institucionalizada ${ }^{79}$, que encuentra su máxima expresión en las reuniones anuales de los directores de las agencias ELSJ ${ }^{80}$, en las que se repasan las principales acciones y retos de cada una y se avanza en la definición y aplicación de una estrategia de cooperación entre ellas ${ }^{81}$.

Se constata, pues, que la práctica institucional se guía cada vez más por la búsqueda de sinergias entre los diversos organismos de la UE y por la potenciación de la transversalidad y la cooperación, por lo que el mapa de las agencias del ELSJ tiende a ampliarse y hacerse más complejo, en la medida en que se refuerzan los objetivos de la UE en este ámbito y crece la necesidad de actuaciones conjuntas. Así, otras agencias de las UE, como, por ejemplo, la Agencia de la Seguridad Marítima, en relación con las actividades de control de fronteras marítimas, o la Agencia de Seguridad de las Redes de la Unión Europea para la lucha contra los ciberdelitos de buen seguro acentuarán en los próximos años su vinculación a los objetivos del ELSJ ${ }^{82}$ e introducirán así nuevos cambios en el mapa de las agencias del ELSJ.

77 Sin ánimo de exhaustividad: Memorandum of Understunding relativo a la cooperación entre FRA y EUROJUST (noviembre 2014), Acuerdo de Cooperación entre FRA y FRONTEX (noviembre 2010), Acuerdo de Trabajo entre EASO y FRA (junio 2013).

78 Sobre la cooperación entre agencias en el ámbito penal, véase A. WEYEMBERGH, I. ARMADA, C. BRIĖRE, The Inter-Agency Cooperation and Future Architecture of EU Criminal Justice and Law Enforcement Area, Parlamento Europeo, Estudio para la Comisión LIBE, 2014.

79 Sobre los orígenes y el desarrollo de las misma, véase FERNÁNDEZ ROJO, op. cit., supra nota 73.

80 Cada año una agencia diferente, de manera rotatoria, ejerce el secretariado de dicha coordinación multilateral. Participan en dicho marco todas las categorizadas en el presente artículo como agencias del ELSJ.

81 Véase el último documento de prioridades adoptado, Multilateral JHA Agencies Scorecard 2015, Documento del Consejo 14784/15, de 1 de diciembre de 2015, y el último informe sobre dicho marco de cooperación multilateral: Final Report of the JHA Agencies Network in 2015, disponible en http://www.eulisa.europa.eu/Publications/ Reports/Final\%20Report\%20JHA\%20Agencies\%20Network\%202015.pdf (consultado por última vez el 22.11.2016).

82 La cooperación entre la nueva Agencia Europea de la Guardia de Fronteras y Costas y la Agencia de la Seguridad Marítima, así como la Agencia Europea de Control de 


\section{UNA NUEVA GOBERNANZA PARA LAS AGENCIAS DEL ELSJ}

La abolición de los pilares por el Tratado de Lisboa ha comportado que el ELSJ (y, por ende, las agencias que en él operan) quede sometido a la lógica institucional del régimen general de los Tratados, lo que ha terminado con la marginación de la Comisión, el PE y el TJUE propia del tercer pilar. El nuevo papel de estas instituciones debería manifestarse tanto en su intervención en el gobierno de las agencias como en el control de estas. Por su parte, el Planteamiento Común sobre las agencias descentralizadas, al reconocer la necesidad de avanzar hacia una cierta homogenización de la estructura de las agencias europeas, sienta unos principios que deberían ser tenidos en cuenta también en el diseño de las agencias del ELSJ.

\section{REEQUILIBRIOS EN LOS ÓRGANOS DE GOBIERNO DE LAS AGENCIAS}

Todas las agencias del ELSJ disponen de un consejo de administración, el máximo órgano de decisión y supervisión de la agencia, cuyo diseño y composición presentan particularidades en función de las agencias, algunas de las cuales han sido o están siendo objeto de revisión precisamente para, entre otras acciones, adaptar dicho órgano al nuevo marco que ofrece el Planteamiento Común y el Tratado de Lisboa ${ }^{83}$. Ejemplo de ello es la propia terminología utilizada para su denominación que, tras la reforma de $\mathrm{CEPOL}^{84}$, deja únicamente a EUROJUST y su "colegio» como caso particular. Esta agencia es también la que presenta mayores singularidades por lo que se refiere a la naturaleza y funciones de dicho órgano, que es a la vez responsable de la organización y funcionamiento de la agencia y colegio de los miembros nacionales encargados de las tareas operativas. Este doble papel de los miembros del colegio, como consejo de administración y representación operativa de sus Estados miembros, ha sido objeto de numerosas críticas al considerar que «no favorece la planificación estratégica a largo plazo [...] y ha impedido la aparición de una identidad común como agencia europea y una visión operativa dentro del consejo de administración» ${ }^{85}$. De ahí que no sea de extrañar que la

Pesca, se menciona expresamente en los arts. 7 y 52 del Reglamento (UE) 2016/1624, loc. cit., supra nota 46.

83 Para un análisis general sobre los órganos de gobierno de las agencias europeas véase M. GROENLEER, The Autonomy of European Agencies, Eburon, Netherlands, 2009.

84 CEPOL disponía de un consejo de gobierno que, en el nuevo reglamento, pasa a denominarse consejo de administración.

85 Comision Europea, Evaluation of the EU Decentralized Agencies in 2009, volume III. individual Agencies, 2009, p. 171. 
propuesta de reforma presentada por la Comisión en 2013 incida precisamente en dicha cuestión. En ella se busca establecer una distinción clara entre las dos composiciones del colegio, en función de si desarrolla funciones operativas o de gestión, como, por ejemplo, la adopción del programa de trabajo, el presupuesto o el informe anual. Para la Comisión:

De esta forma, se introduce un doble nivel de gobernanza, según lo previsto en el enfoque común, a la vez que se preserva la naturaleza especial de EUROJUST y se protege su independencia. Esto también resulta rentable, además de contribuir a la eficiencia de EUROJUST, ya que los miembros nacionales contarán con asistencia en cuestiones presupuestarias y administrativas, por lo que podrán centrarse en sus labores operativas ${ }^{86}$.

Pero esta propuesta no ha sido bien acogida en el Consejo, que es partidario de mantener la situación actual, es decir, una sola formación para el colegio $^{87}$, lo cual, como veremos a continuación, tiene importantes consecuencias en relación con la participación de la Comisión en dicho órgano.

En cuanto a la composición de los consejos de administración, el Planteamiento Común apuesta por incluir a un representante de cada Estado miembro ${ }^{88}$, dos representantes de la Comisión y, en su caso, un representante del PE y de otras partes interesadas. El primer punto - la representación de los Estados miembros - no exige especiales adaptaciones en el caso de las agencias del ELSJ que, como ya se ha indicado, presentan un marcado signo intergubernamental, aunque sí deben reseñarse algunos aspectos particulares $^{89}$. En primer lugar, EIGE no cuenta con un representante de todos los

86 COM (2013) 535 final, loc. cit., supra nota 31, p. 5, supra nota 32.

87 Proposal for a Regulation on the European Union Agency for Criminal Justice Cooperation (EUROJUST) [First reading]. Partial General approach, doc. 6643/15 del Consejo, de 27 de febrero de 2015.

88 La presencia de los Estados miembros se ha justificado por la doctrina como reflejo de su participación en el ejecutivo comunitario y ha sido finalmente aceptada por la Comisión a pesar de que en algunos momentos defendió una composición más limitada de los mismos, como se reseña en VOS, op. cit., p. 26, supra nota 15.

89 La composición de los consejos de administración de las agencias del ELSJ que se reseña a continuación se encuentra regulada en el art. 10 del Reglamento EIGE (loc. cit., supra nota 57), art. 12 del Reglamento FRA (loc. cit., supra nota 56), art. 9 del Reglamento OEDT (loc. cit., supra nota 59), art. 13 del Reglamento EULISA (loc. cit., supra nota 54), art. 25 del Reglamento EASO (loc. cit., supra nota 36), arts. 63 y 66 del Reglamento FRONTEX(loc. cit., supra nota 46), art. 8 del Reglamento CEPOL (loc. cit., supra nota 29) y art. 10 del Reglamento EUROPOL (loc. cit., supra nota 30). 
Estados miembros, sino que su consejo de administración está compuesto por dieciocho representantes nombrados por el Consejo, siguiendo el orden de rotación de la Presidencia, sobre la base de una propuesta de cada Estado miembro implicado. El carácter excepcional e innovador de dicha composición se explica por el tamaño extremadamente reducido de la agencia, por el alcance limitado y específico de sus objetivos y funciones y por la fuerte influencia en esta de la Comisión, en la medida en que asume algunas de las tareas que hasta su creación desempeñaba dicha institución. En segundo lugar, la FRA no cuenta estrictamente con representantes estatales en su consejo de administración, sino con personalidades independientes, que deberán ser expertos en derechos humanos, designadas por los Estados miembros. La razón de ello estriba en la necesidad de garantizar al máximo la independencia de la agencia por su función y objetivos, en la línea de los denominados Principios de París sobre los Órganos de los Derechos Humanos ${ }^{90}$. Por último, otras especificidades de la representación de los Estados miembros en algunas agencias del ELSJ se deben a la geometría variable que presenta su participación en este ámbito material. Como es bien sabido, ni Reino Unido ni Irlanda forman parte del Espacio Schengen, y los Protocolos núm. 21 y 22 establecen un opting-out para Reino Unido, Irlanda y Dinamarca en la regulación del ELSJ. Ello explica, por ejemplo, que Irlanda y Reino Unido figuren en el consejo de administración de FRONTEX como invitados y que Dinamarca participe como observador en EASO y con voto limitado en EULISA.

En cuanto a la Comisión, su presencia en los consejos de administración de las agencias del ELSJ está garantizada en todas aquellas que se han creado con posterioridad a la entrada en vigor del Tratado de Lisboa, traduciendo de esta manera el nuevo equilibrio institucional. Los reglamentos de base tanto de EASO como de EULISA prevén efectivamente que sus consejos de administración cuenten con dos representantes de la Comisión, alineándose así con el Planteamiento Común. Pero, respecto a las agencias creadas con anterioridad a la reforma de Lisboa, el panorama varía entre las agencias del primer y del tercer pilar: la Comisión cuenta con dos representantes en los consejos de administración de FRA, FRONTEX y el OEDT, con un representante en EUROPOL, CEPOL y EIGE ${ }^{91}$, y con ninguno en EUROJUST. En su propuesta de reforma de EUROPOL, la

90 Aprobados por la Asamblea General de las Naciones Unidas en su Resolución A/ RES/48/134, de 20 de diciembre de 1993.

91 La presencia de un único representante de la Comisión en EIGE no debe interpretarse como una menor influencia, sino que se explica por la composición más reducida de su consejo de administración, en el que como ya se ha dicho no están presentes todos 
Comisión preveía adaptar la composición de su consejo de administración a lo dispuesto en el Planteamiento común y aumentar su representación a dos miembros, pero este cambio no ha sido retenido en el acuerdo final, de manera que la Comisión seguirá estando infrarrepresentada en el consejo de administración de dicha agencia. Por su parte, CEPOL era una de las agencias que no contaba con representación de la Comisión, una ausencia que se ha corregido en la reciente reforma, incorporando a su consejo de administración un representante de la Comisión, pero no dos, tal como proponía la Comisión. En la misma línea, tampoco está prevista actualmente la representación de la Comisión en EUROJUST, y también este es uno de los aspectos que la Comisión pretende modificar en su propuesta del nuevo reglamento, incluyendo dos representantes en el colegio de EUROJUST cuando este ejerza funciones de gestión, es decir, cuando actúe como un órgano de gobierno de la agencia, en contraposición a cuando ejerza funciones operativas, en cuyo caso solo estaría formado por los miembros nacionales de EUROJUST. Como ya se ha señalado, el Consejo es partidario de mantener una única formación para el colegio, lo cual tiene como consecuencia que la Comisión no pueda participar en él. La posición del Consejo ni siquiera incluye la presencia de la Comisión en las reuniones del colegio de EUROJUST que traten asuntos administrativos o de gestión. Se apuesta, pues, por mantener el diseño actual, que no se corresponde ni con el nuevo equilibrio institucional aportado por el Tratado de Lisboa ni con el Planteamiento Común. Como se ha señalado, el bajo peso de la Comisión frente a los Estados puede peligrar la presencia de los intereses de la UE en las acciones de estas agencias ${ }^{92}$.

En cuanto a la participación del PE, el Planteamiento Común la contempla para casos específicos, sin explicitar los motivos que podrían justificarla. En el ámbito del ELSJ, el único caso reseñable es el OEDT, en la medida en que el PE designa como miembros de su consejo de administración a dos expertos independientes especialmente conocedores del mundo de las drogas, lo que no puede considerarse una representación de la institución en sentido estricto. Ni las agencias creadas después de la entrada en vigor del Tratado de Lisboa ni las propuestas de reforma que están barajando las instituciones incluyen la participación del PE en el consejo de administración, por lo que cabe concluir que se ha optado por otorgar al PE un papel de control ex post,

los Estados miembros, por lo que el peso relativo del representante de la Comisión es mayor.

92 JORDANA, op. cit., p. 33, supra nota 23. 
lo cual, en nuestra opinión, resulta coherente con sus funciones en el sistema institucional de la $\mathrm{UE}^{93}$.

La segunda pieza clave en la estructura y el funcionamiento de una agencia es su director ${ }^{94}$, en la medida en que este es el máximo responsable de las decisiones que permiten ejecutar el programa de trabajo, el presupuesto y la gestión diaria de la agencia. También es quien prepara las decisiones del consejo de administración y el representante legal de la agencia. De aquí que la influencia y el equilibrio de poderes de las instituciones europeas y los Estados en el gobierno de las agencias se refleje también en su elección. Al respecto, en el Planteamiento Común puede leerse: "Con el fin de respetar la autonomía de las agencias, corresponderá al consejo de administración nombrar a los directores, basándose en una lista elaborada por la Comisión según un procedimiento de selección abierto y transparente que garantice una evaluación rigurosa de los candidatos y un alto nivel de independencia. En circunstancias específicas y justificadas podrán hacerse excepciones a este planteamiento» ${ }^{95}$.

Las dos agencias creadas más recientemente, EASO y EULISA, siguen plenamente este modelo. En efecto, en ambos casos se prevé que la Comisión organizará un concurso general, previo anuncio en el Diario Oficial de la UE y en otros medios (garantizando pues la transparencia y la evaluación) y propondrá al consejo de administración una lista de candidatos elegibles para que proceda a su nombramiento. El consejo de administración podrá requerir la repetición del procedimiento si considera que los candidatos propuestos no son idóneos. También en ambos casos se prevé que, antes de procederse al nombramiento, el candidato seleccionado realizará una declaración ante la comisión competente del PE y se someterá a las preguntas de sus miembros, tras lo cual el PE adoptará un dictamen con su opinión sobre el candidato. El

93 Hay que señalar que algunas agencias del ELSJ prevén la presencia de otros actores en sus consejos de administración, en la línea del Planteamiento Común, que, como ya se ha dicho, contempla la posibilidad de que partes interesadas participen en dichos órganos. Se trata de expertos, como en el caso de la FRA (que cuenta con un experto designado por el Consejo de Europa), de representantes de otras organizaciones internacionales (como en el caso de EASO, que prevé la presencia, aunque sin voto, de un representante de ACNUR) o de Estados terceros (como los Estados asociados al espacio Schengen en FRONTEX y EULISA). Las agencias, también las del ELSJ, cuentan con otros órganos, que son mencionados también en el Planteamiento Común, tales como comités científicos o de expertos o redes, que no serán analizados aquí por tener una incidencia menor en el gobierno de la agencia.

95 Declaración Común, loc. cit., párr. 16, supra nota 14. 
consejo de administración deberá informar al PE de la manera en que ha tenido en cuenta dicho dictamen, que será confidencial hasta el nombramiento ${ }^{96}$.

Un patrón similar se ha seguido para las agencias creadas con anterioridad a Lisboa cuya base jurídica radicaba en el primer pilar, es decir, en el antiguo TCE, aunque con algunas variaciones y especificidades, que no afectan en ningún caso al órgano competente para el nombramiento, que es el consejo de administración de la agencia. Así, en cuanto a la propuesta de nombramiento, se observa una coincidencia en atribuir a la Comisión el establecimiento de una lista de candidatos entre los cuales deberá ser elegido el futuro director, variando el grado de precisión acerca del procedimiento a seguir ${ }^{97}$. En cuanto a la intervención del PE en el procedimiento, para el EIGE y el OEDT, se establece que el candidato seleccionado por el consejo de administración, antes de su nombramiento, comparecerá ante la comisión parlamentaria competente, aunque sin aludir a la emisión de ningún dictamen que recoja la opinión del PE. El supuesto más particular es el de FRA, en el que son todos los candidatos seleccionados por la Comisión los que deben presentarse y responder a las preguntas no solo del PE, sino también del Consejo. Dichas instituciones emitirán un dictamen en el que se indicará el orden de sus preferencias. El nombramiento final por parte del consejo de administración de la agencia deberá tener en cuenta dichos dictámenes. Un procedimiento parecido es el que se ha retenido para el nuevo FRONTEX ${ }^{98}$, que prevé también la presentación de todos los candidatos propuestos ante las comisiones parlamentarias competentes, que adoptarán un dictamen y la necesidad de que el consejo de administración de la agencia justifique su posición en caso de que no elija al candidato preferido del PE.

Vemos, pues, que en todas estas agencias el procedimiento de elección del director responde a un equilibrio de poderes según el cual las instituciones

96 La única diferencia relevante entre ambos es que en el caso de EASO se establece que el PE «podrá» realizar un dictamen, mientras que para EULISA directamente se dice que el PE «realizará» un dictamen, Art. 18 Reglamento EULISA (cit., nota 53), y art. 30 Reglamento EASO (loc. cit., nota 36).

97 En algunos casos, el Reglamento de base de la agencia precisa el procedimiento a seguir, indicando que debe tratarse de un concurso general (art. 12 Reglamento EIGE, loc. cit, supra nota 57) o de un procedimiento de selección abierto y transparente (art. 15 Reglamento FRA, loc. cit, supra nota 56), mientras que en otros solo se indica la necesidad de publicar la vacante en el Diario Oficial u otros medios (art. 69 FRONTEX, loc. cit, supra nota 46), y en algunos no se dice nada al respecto (art. 11 Reglamento OEDT, loc. cit, supra nota 60).

Ello supone una novedad interesante, puesto que la anterior reglamentación de FRONTEX no preveía ninguna participación del PE en la elección de su director. 
europeas participan con una capacidad de propuesta y de consulta, con un peso creciente del PE, y la decisión final recae en el consejo de administración, formado mayoritariamente por representantes de los Estados miembros. Obsérvese, en este sentido, que los consejos de administración de las agencias pueden ser considerados órganos híbridos que participan en la toma de decisiones de la agencia y que, a la vez, ejercen actividades típicas de control, como, por ejemplo, el nombramiento o la posibilidad de cesar al director. La composición mayoritariamente intergubernamental de dichos consejos muestra claramente la voluntad de influencia y control sobre las agencias que poseen los Estados.

Sin embargo, las agencias creadas en virtud del tercer pilar reflejan un equilibrio diferente, incluso después de haber sido reformadas tras el Tratado de Lisboa. En efecto, tanto en el caso de CEPOL como de EUROPOL, la Comisión proponía adaptar la elección de su director a lo establecido en el Planteamiento Común ${ }^{99}$, pero, en ambos casos, el Reglamento finalmente adoptado no ha seguido por completo dicha propuesta ${ }^{100}$. Por lo que se refiere a CEPOL, la designación de tres candidatos a partir de la cual el consejo de administración realizará el nombramiento no es una competencia exclusivamente de la Comisión, sino de un comité de selección establecido por el consejo de administración, que constará de miembros designados por los Estados y la Comisión. En el caso de EUROPOL, el director será nombrado por el Consejo a partir de una lista de candidatos que le presentará el consejo de administración y que habrán sido seleccionados, mediante un procedimiento abierto y transparente, por un comité de selección formado por representantes de los Estados y un representante de la Comisión. Antes del nombramiento, podrá invitarse al candidato seleccionado por el Consejo a que comparezca ante la comisión competente del PE, que emitirá un dictamen no vinculante.

Por último, en lo que se refiere a EUROJUST, el director administrativo de la agencia es designado por el colegio de EUROJUST por una mayoría cualificada de dos tercios a partir de una lista de candidatos elaborada por un comité de selección en el que está previsto que participe la Comisión. En el

99 Es preciso tener en cuenta que, antes de la reforma, la Comisión no tenía ninguna participación en dicho procedimiento. En el caso de CEPOL, el director era nombrado por el consejo de administración a partir de una lista de candidatos propuesta por un comité de selección. En el caso de EUROPOL, el director era nombrado por el Consejo a partir de una lista de al menos tres candidatos propuestos por el consejo de administración. En ninguno de los casos se exigía que el procedimiento de selección fuese abierto y transparente.

100 Art. 9 Reglamento CEPOL (loc. cit, supra nota 29) y art. 11 Reglamento EUROPOL (loc. cit, supra nota 30). 
marco de la reforma que se está discutiendo, este ha sido también un punto conflictivo. Mientras que la Comisión ha propuesto un procedimiento de selección homologado con el resto de las agencias (es decir, una lista de candidatos elaborada por la Comisión y elección por el consejo de administración), el Consejo pretende reducir la influencia de la Comisión y opta por una lista de candidatos elaborada por el consejo ejecutivo de EUROJUST, un órgano en que está presente la Comisión, pero de manera marginal.

Vemos, pues, que, a pesar de las reformas, las agencias del ELSJ que tuvieron su origen en el antiguo tercer pilar continúan hoy reflejando un equilibrio institucional en el que el Consejo y los Estados miembros mantienen un mayor protagonismo frente a la Comisión, y que constituyen excepciones a las directrices establecidas en el Planteamiento Común. A pesar de la desaparición de los pilares, la impronta intergubernamental pervive en las agencias de la cooperación policial y judicial ${ }^{101}$.

\section{HACIA UN MAYOR CONTROL DEMOCRÁTICO}

La preocupación por la necesidad de establecer mecanismos de control que actúen como contrapeso al elevado nivel de autonomía de las agencias es una constante ${ }^{102}$ de la que se hace eco el Planteamiento Común, dedicando un apartado específico a las cuestiones relacionadas con la responsabilidad y el control de las agencias europeas. Esta preocupación es, si cabe, más acuciante en el caso de las agencias del ELSJ, ya que abordan temas especialmente sensibles, tanto desde la óptica de la seguridad como de los derechos de las personas.

Definido en términos amplios, el concepto de control se entiende como la «capacidad de influir en un actor por parte de otro». Ello incluye un control ex ante - que permite incidir en la creación y en el funcionamiento de las agencias- y un control ex post - que encaja con el concepto de rendición de cuentas (accountability) ${ }^{103}$, entendiendo por este la obligación de explicar y

101 En este sentido, véase BUSUIOC, op. cit., p. 22, supra nota 20.

102 Sobre este debate, véase S. CARRERA, L. DEN HERTOG, J. PARKIN, «The Peculiar Nature of EU Home Affairs Agencies in Migration Control: Beyond Accountability versus Autonomy?», European Journal of Migration and Law, vol. 5, núm. 4, 2013, pp. 337-358. Sobre la autonomía de las agencias y sus límites, véase GROENLEER, op. cit., supra nota 83.

103 Sobre las diferencias conceptuales entre control y accountability, véase BUSUIOC, $o p$. cit., p. 48, supra nota 20. 
justificar las conductas llevadas a cabo ${ }^{104}$ - Mientras que la intensificación de mecanismos de control tiende a limitar la autonomía de las agencias, la rendición de cuentas es compatible con ella y la complementa ${ }^{105}$.

Respecto al control ex ante, las principales novedades han sido ya comentadas en apartados anteriores: el paso al procedimiento legislativo ordinario que garantiza la intervención de la Comisión y el PE en el diseño de las agencias $^{106}$, la apuesta por la participación de la Comisión en los consejos de administración o la intervención de la Comisión y el PE en el procedimiento de elección del director de las agencias. A ello hay que añadir que el Planteamiento Común prevé un sistema de alerta o aviso que puede activar la Comisión cuando tenga serios motivos de inquietud en relación con que el consejo de administración de una agencia vaya a tomar decisiones que pudiesen incumplir el mandato de la agencia, vulnerar la legislación de la UE o estar en contradicción manifiesta con los objetivos políticos de la UE. En estos casos, la Comisión planteará oficialmente el tema ante el consejo de administración y le pedirá que se abstenga de adoptar la decisión de que se trate. Si el consejo de administración desoye su petición, informará al PE y al Consejo, para que las tres instituciones puedan reaccionar. La Comisión podrá solicitar al consejo de administración que suspenda la aplicación de la decisión controvertida mientras las tres instituciones examinan el asunto, pero en ningún caso tiene potestad para suspender directamente las decisiones del consejo de administración. Este mecanismo, que no ha sido utilizado en ninguna ocasión hasta ahora, debe considerarse un instrumento de ultima ratio que puede desempeñar un papel de carácter básicamente disuasorio ${ }^{107}$.

${ }^{104}$ M. BOVENS, «Analysing and Assessing Accountability: A Conceptual Framework», European Law Journal, vol. 13, 2007, pp. 447-468, p. 450.

${ }^{105}$ M. BUSUIOC, M. GROENLEER, «Beyond Design: The Evolution of Europol and Eurojust», en KAUNERT; LÉONARD; OCCHIPINTI, op. cit., pp. 13-32, p. 14, supra nota 2.

106 Para una relativización del impacto en la práctica de los nuevos poderes de decisión del PE en el ámbito del ELSJ, véase F. TRAUNER, A. RIPOLL, "The Communitarization of the Area of Freedom, Security and Justice: Why Institutional Change does not Translate into Policy Change», Journal of Common Market Studies, vol. 54, núm. 6, pp. 1417-1432.

107 Como origen de esta medida VOS apunta a las fuertes polémicas ocasionadas en torno al Observatorio para el Racismo y la Xenofobia, en concreto por un informe sobre antisemitismo que inicialmente el Observatorio decidió no publicar y en general por sus diferencias de criterio con la Comisión acerca de cómo desempeñar sus objetivos (VOS, op. cit., p. 32, supra nota 15). Sobre las relaciones entre la Comisión y el Observatorio, véase GROENLEER, op. cit., pp. 243-273, supra nota 83. 
Por lo que se refiere al control ex post o rendición de cuentas, el control político se articula básicamente a través de la obligación de presentar de forma sistemática una serie de informes a las instituciones europeas para que puedan efectuar un seguimiento de las actividades de las agencias y presentar, en su caso, las observaciones oportunas. También, en este terreno, el PE ha visto incrementada su participación ${ }^{108}$.

El mecanismo más generalizado en este ámbito consiste en la obligación que tienen las agencias de presentar anualmente un Informe General de Actividades. Todas las agencias del ELSJ que fueron creadas antes de la reforma de Lisboa en virtud del primer pilar (FRONTEX, FRA, EIGE, OEDT) contemplan la obligación de presentar dicho informe al PE, así como al Consejo y a la Comisión. En algunos casos, esta presentación se hace extensiva a otras instituciones y órganos de la UE, como el Tribunal de Cuentas, el Comité Económico y Social y el Comité de las Regiones. Lo mismo puede afirmarse de las agencias que se crearon ya en virtud del TFUE (EASO, EULISA). Por lo que se refiere a las agencias originarias del tercer pilar, la única que contemplaba esta obligación y la ha mantenido en su nuevo reglamento es CEPOL. En cambio, tanto para EUROJUST como EUROPOL, su obligación de rendir cuentas sobres sus actividades ante el PE se ha articulado hasta ahora de una forma indirecta: el informe anual se presenta ante el Consejo, y es este quien informará al PE. La reforma prevista de ambas agencias modifica este punto y prevé la presentación directamente ante el PE y los parlamentos nacionales. La participación de estos últimos es precisamente una de las novedades destacables en torno a este control político, que en el caso de EUROPOL y EUROJUST está prevista explícitamente en los arts. 85 y 87 del TFUE. Esta previsión debe valorarse en términos positivos como un incremento del control democrático. Para dar cumplimiento a esta exigencia, el nuevo reglamento de EUROPOL establece el denominado Grupo de Control Parlamentario Conjunto (GCPC), creado por los parlamentos nacionales y la comisión competente del $\mathrm{PE}$, que determinarán conjuntamente su organización y su reglamento interno. Dicho GCPC tiene como misión efectuar la supervisión política de EUROPOL, señalándose expresamente que ello

108 Sobre el creciente papel del PE en el control de las agencias del ELSJ, véase F. TRAUNER, «The European Parliament and Agency Control in the Area of Freedom, Security and Justice», West European Politics, vol. 35, núm. 4, 2012, pp. 784-802. Más en general, sobre el control del PE sobre las agencias, véase F. JACOBS, «EU Agencies and the European Parliament», en EVERSON; MONDA; VOS, op. cit., pp. 201228, supra nota 15 . Véase G. GARZÓN CLARIANA, «El control parlamentario del ejecutivo en la Unión Europea», en F. PAU I VALL (coord.), El control del Gobierno en democracia, Tecnos, Madrid, 2013, pp. 19-40. 
incluye las consecuencias de las actividades de EUROPOL sobre los derechos fundamentales y las libertades de los particulares.

Otro mecanismo habitualmente previsto de rendición de cuentas es el envío al PE del Programa de Trabajo Anual. De nuevo se trata de una obligación presente en las agencias del primer pilar o de nueva creación, pero que no estaba contemplada en las agencias del tercer pilar, y que se equipara en el nuevo diseño de estas.

Estas obligaciones generales se complementan con la presentación de informaciones suplementarias específicas de cada una de las agencias. Un muy buen ejemplo de ello lo constituye el nuevo reglamento de FRONTEX, que, en coherencia con la declaración general de que la agencia es responsable ante el PE y el Consejo, prevé en numerosos artículos la obligación de informar al PE sobre cuestiones concretas, tales como el número de agentes de la guardia de fronteras que cada Estado miembro ponga a disposición de los equipos europeos, los equipos técnicos que cada Estado aporte, los análisis de riesgos generales y las evaluaciones de vulnerabilidad de cada Estado, así como de los acuerdos y relaciones de FRONTEX con otras agencias de la UE, organizaciones internacionales o Estados terceros, entre otros. Una lógica similar encontramos en EUROPOL, que deberá suministrar de manera sistemática al PE y a los Parlamentos nacionales una serie de informes y documentos relativos a las evaluaciones de las amenazas, análisis estratégicos e informes generales de situación, así como los resultados de estudios y evaluaciones encargados por la agencia, los acuerdos administrativos suscritos con terceros países, la cantidad y la calidad de la información facilitada a EUROPOL por cada Estado miembro y sobre la actuación de su unidad nacional. La transmisión de dichas informaciones debe realizarse respetando las exigencias de confidencialidad y discreción, por lo que se ha previsto la conclusión de un convenio de colaboración sobre el acceso a la información clasificada y a la información sensible no clasificada tratada por o a través de EUROPOL.

Por último, aunque no menos importante, hay que mencionar las distintas previsiones de que los directores o los presidentes de los consejos de administración de las agencias comparezcan ante el PE (y en su caso el Consejo) para informar sobre las actuaciones de las agencias y someterse a las preguntas de los diputados de las comisiones parlamentarias competentes, aunque debe resaltarse la falta de uniformidad en cuanto al carácter obligatorio de dicha comparecencia. Mientras que algunos Reglamentos la regulan en términos de posibilidad (el director «podrá» comparecer si se le invita ${ }^{109}$ ),

109 La doctrina ha criticado dicha falta de obligación. Por ejemplo J. Santos, que recoge el hecho de que en el pasado directores de FRONTEX han declinado participar en 
la fórmula utilizada en algunas de las agencias más recientes (EASO, la reforma de CEPOL y de EUROPOL) apunta a una obligación (el director "comparecerá», «informará»).

Vemos, pues, que, además del tradicional control presupuestario que el PE ya venía ejerciendo con anterioridad sobre las agencias ${ }^{110}$, el nuevo marco jurídico apuesta por una mayor implicación política de dicha institución. Ahora bien, más allá de los cambios formales, se precisa que el PE y, en concreto, la comisión LIBE se muestren activos en el ejercicio de dicho control y exijan que la información que reciban sea adecuada, que sus preguntas reciban respuestas y que las agencias tomen en consideración sus inquietudes ${ }^{111}$. Para fomentar esta mayor implicación en el control, y a la vez encontrar una mejor solución para las exigencias de confidencialidad, se ha sugerido la creación de un subcomité LIBE dedicado únicamente a la supervisión parlamentaria de las agencias del ELSJ ${ }^{112}$. En el caso concreto de EUROPOL, la creación de un Grupo de Control Parlamentario Conjunto dedicado específicamente a la supervisión de dicha agencia puede ser también un buen mecanismo para fomentar una mayor implicación y especialización en la materia entre los miembros de dicho Grupo.

\section{EL CONTROL JURISDICCIONAL}

El control ex post de las actividades de las agencias del ELSJ no solo tiene una dimensión política, sino que debe contemplar necesariamente también un control jurisdiccional de legalidad. Como se ha mencionado, la reforma

debates organizados por el Parlamento sobre la gestión de la frontera marítima del sur de Europa, J. SANTOS, «Análisis del marco jurídico-político de la dimensión exterior de las agencias del espacio de libertad, seguridad y justicia", en PI; ZAPATER, op.cit., pp. 9-34, p. 28, supra nota 36.

110 Todos los Reglamentos de base de las agencias prevén la intervención del PE, en tanto autoridad presupuestaria junto con el Consejo, tanto en la elaboración del presupuesto como en el control de su ejecución, mediante su descargo. Sobre esta cuestión véase D. WARIN, «Le rôle du Parlement européen dans le contrôle des agences de l'espace de liberté, sécurité et justice», en BLASI; ILLAMOLA, op. cit., pp. 11-20, supra nota 23.

111 BUSUIOC Y CURTIN afirman: «[...] la investigación previa sobre la responsabilidad de las agencias europeas revela la presencia de una amplia gama de mecanismos de responsabilidad existentes en manos de diversos foros institucionales; lo que suscita preocupación es el escaso uso de los mecanismos existentes»; BUSUIOC, CURTIN, op. cit., p. 19, supra nota 20.

112 Propuesta valorada positivamente por SANTOS, op. cit., p. 28, supra nota 109. 
de Lisboa ha supuesto la extensión del control del TJUE a todas las agencias europeas, al incluir una referencia a los órganos y organismos de la UE en la regulación de determinadas vías de recurso ${ }^{113}$, destacando en primer lugar el control de la legalidad vía el recurso de anulación (art. 263 del TFUE). Más que una gran novedad, dicha reforma implica la codificación de una jurisprudencia anterior, puesto que el Tribunal General ya había aceptado el control de los actos adoptados por las agencias que producen efectos jurídicos frente a terceros ${ }^{114}$. Lo que sí resulta novedoso es la extensión de dicho control a todas las agencias del ELSJ, puesto que, con anterioridad a Lisboa, las agencias del tercer pilar se veían afectadas por las restricciones que la regulación de este ámbito intergubernamental imponía a la jurisdicción del TJUE.

Ahora bien, la utilización del recurso de anulación solo es posible contra actos definitivos que produzcan efectos jurídicos frente a terceros, y las agencias del ELSJ, como ya se ha explicado, carecen de una capacidad reguladora, por lo que es poco probable que puedan plantearse cuestiones relacionadas con un control de legalidad de sus actos vía recurso de anulación. Esta afirmación requiere, sin embargo, algunas matizaciones. En primer lugar, como también se ha visto, algunas de estas agencias desarrollan, y cada vez más, una importante tarea de consultas, suministro de información, elaboración de dictámenes, entre otras, que son tenidas en cuenta por las instituciones europeas. Como señala Esteve:

[...] persisten, pues, zonas de dudas sobre determinados actos de las agencias que no pueden ser considerados formalmente o claramente como «actos destinados a producir efectos jurídicos frente a terceros», por constituir actos intermedios, consultivos o actos internos, pero que de facto llegan a tener una gran relevancia o influencia en la decisión final que adopta una determinada institución europea [...] La valoración de si un determinado acto produce o no efectos jurídicos a terceros va a requerir cada vez más un análisis casuístico de la medida y de los efectos que haya producido en un contexto determinado ${ }^{115}$.

113 Sobre esta cuestión, véase M. CHAMON, «Les agences décentralisées et le droit procédural de l'UE», $C D E$, vol. 52, núm. 2, 2016, pp. 541-574.

114 En la Sentencia Sogelma, en la que se discutía una decisión de la Agencia Europea de Reconstrucción sobre un procedimiento de licitación, el Tribunal General afirmó que «todo acto que emane de un organismo europeo destinado a producir efectos jurídicos hacia terceros debe ser susceptible de un control jurisdiccional», Sentencia del Tribunal de Primera Instancia, Sogelma/AER, T-411/06, ECLI:EU:T:2008:419, apdo. 37.

115 F. ESTEVE, «El control judicial de las agencias del Espacio de Libertad, Seguridad y Justicia», en BLASI, ILLAMOLA, op. cit., pp. 81-104, p. 88, supra nota 23. 
Similar argumento puede desarrollarse en relación con determinados actos en el contexto de la preparación, coordinación y desarrollo de determinadas acciones operativas, en las que con independencia de la denominación del acto no puede descartarse que algunas decisiones conlleven efectos jurídi$\cos ^{116}$.

En segundo lugar, como se ha visto en los apartados anteriores, el proceso de reformas que está afectando a algunas agencias refuerza sus capacidades de imponer ciertas obligaciones a los Estados, ya sea en cuanto al suministro de datos e informaciones, como en EUROPOL, o de equipos técnicos y recursos humanos, como en el nuevo FRONTEX. Recuérdese también que en el art. 3 del Reglamento de esta última se establece que las estrategias nacionales de control de fronteras «serán conformes» con la estrategia europea adoptada por la agencia. Aunque la naturaleza de estos actos de las agencias dista de ser clara a partir de la simple lectura de la reglamentación y esta todavía no se ha aplicado, no es descabellado pensar que los Estados puedan recurrir al TJUE para discutir la legalidad de dichos actos.

En tercer lugar, algunas de las agencias del ELSJ disponen de procedimientos administrativos de control específicos, ya sea en el campo de la protección de datos (como EUROPOL o EUROJUST) o del respeto de los derechos humanos (FRONTEX). En este sentido, el nuevo Reglamento de EUROPOL prevé expresamente que las decisiones adoptadas por el supervisor europeo de Protección de Datos sobre el tratamiento de datos por parte de la agencia serán recurribles ante el TJUE ${ }^{117}$. Asimismo, en dicho Reglamento se especifican las obligaciones de EUROPOL en materia de transparencia, quedando sometida al cumplimiento de las obligaciones derivadas del Reglamento núm. 1049/2001 relativo al acceso a los documentos. Las decisiones tomadas por la agencia en esta materia podrán ser recurridas ante el TJUE, lo cual es aplicable al resto de las agencias ${ }^{118}$. En el caso del nuevo mecanismo de denuncias individuales por violación de los derechos humanos ante FRONTEX, que permite a los particulares denunciar ante el Agente de Derechos Fundamentales de la agencia supuestas violaciones de derechos cometidas en

116 Sobre la utilización de actos de softlaw por parte de las agencias, véase E. CHITI, «European Agencies' Rulemaking: Powers, Procedures and Assessment», European Law Journal, vol. 19, núm. 1, 2013, pp. 93-110.

117 Para un examen del nuevo procedimiento de protección de datos en EUROPOL, véase BLASI, op. cit., pp. 214-220, supra nota 31; y A. GUTIÉRRRZ ZARZA, «El régimen de protección de datos de las agencias del Espacio LSJ", en BLASI, ILLAMOLA, op. cit., pp. 135-160, supra nota 23.

118 El art. 74.5 del Reglamento del nuevo FRONTEX (loc. cit., supra nota 46) así lo reconoce expresamente. 
el transcurso de operaciones llevadas a cabo por la agencia ${ }^{119}$, nada se dice en el Reglamento sobre un posible recurso ante el TJUE. Este silencio no debe ser óbice, en nuestra opinión, para considerar que una decisión del Agente de Derechos Fundamentales que implicara, por ejemplo, no admitir una denuncia, debe considerarse como un acto que produce efectos jurídicos frente a terceros y por tanto también susceptible de control jurisdiccional por la vía del recurso de anulación.

Por lo demás, junto al recurso de anulación contra decisiones adoptadas por las agencias, su actividad también podría ser enjuiciada por el TJUE por la vía del recurso por responsabilidad extracontractual, destinado a reparar un perjuicio causado por un acto o por un comportamiento imputable a una institución o un órgano de la UE. La legitimación activa corresponde a cualquier persona física o jurídica, así como a los Estados miembros, que tengan un interés legítimo, es decir que hayan sufrido un daño. Aunque en la regulación de dicho recurso por el Tratado (arts. 268 y 340 del TFUE) no se menciona expresamente a los órganos u organismos sino solo a las instituciones y sus agentes, el TJUE ha entendido, como no podía ser de otra manera, que el daño causado por las instituciones de la UE o sus agentes «se extiende a todos los organismos comunitarios constituidos por el Tratado y cuya misión es contribuir a los objetivos de la Comunidad ${ }^{120}$. Esta vía de recurso es, pues, plenamente practicable también en relación a las agencias del ELSJ. De hecho, la normativa de algunas de ellas alude expresamente a dicha posibilidad. Así, el nuevo Reglamento de EUROPOL precisa en su art. 49 que esta indemnizará los daños causados por sus servicios y que el TJUE será competente para conocer de los litigios relativos a estos. En el supuesto en que los daños tengan su origen en un tratamiento ilícito de datos personales, la responsabilidad podrá reclamarse a EUROPOL o al Estado de origen de la información. En caso de discusión sobre el reparto de estas responsabilidades, el art. 50 del nuevo Reglamento prevé la intervención del consejo de administración de la agencia, «sin perjuicio del derecho a impugnar dicha decisión de conformidad con el art. 263 TFUE».

119 Para un análisis crítico de este mecanismo, véase C. PÉREZ GONZÁLEZ, «De FRONTEX a la Agencia Europea de la Guardia de Fronteras y Costas: ¿Cambia todo para que todo siga igual? A propósito de la necesidad de mejorar la protección de los derechos fundamentales», en BLASI; ILLAMOLA, op. cit., pp. 191-208, supra nota 23.

120 Sentencia del Tribunal de Justicia, Defensor del Pueblo/Lamberts, C-234/02 P, ECLI:EU:C:2004:174. apdo. 49. 
También, en relación con las actividades de FRONTEX, se ha suscitado la posibilidad de que su participación en acciones operativas genere una responsabilidad por daños, especialmente en lo que se refiere al respeto de los derechos fundamentales. El nuevo Reglamento de esta agencia prevé en su art. 60 la competencia del TJUE para dilucidar la responsabilidad de la agencia por daños y la obligación de esta de repararlos. Ahora bien, el principal problema jurídico que plantea esta posibilidad es el complicado reparto de responsabilidades entre la agencia y los Estados miembros, en la medida en que la acción de FRONTEX se limita a la coordinación, cuestión aún más compleja si cabe en operaciones conjuntas llevadas a cabo en territorio de terceros Estados. Como ha señalado el PE, la acción de FRONTEX no puede disociarse de la actividad llevada a cabo por los Estados bajo su coordinación, por lo que no puede excluirse su responsabilidad extracontractual ${ }^{121}$. Asimismo, debe señalarse que el papel de FRONTEX a menudo excede de lo que podría considerarse una mera coordinación, ya que asume tareas de planificación y de impulso ${ }^{122}$.

En esta lista ejemplificativa de situaciones susceptibles de ser atendidas por el TJUE, cabe citar también la actuación conjunta de las agencias en los hotspots, a la que se ha aludido en apartados anteriores, aunque también aquí pueden generarse problemas de reparto de responsabilidades; en este caso, no solo en relación con los Estados, sino entre las distintas agencias que actúan de manera conjunta en dichos puntos ${ }^{123}$. Por ello, se ha sugerido por parte de la doctrina la conveniencia de regular por medio de un instrumento legislativo el funcionamiento de dichos puntos que clarifique las distintas competencias de cada una y que prevea un mecanismo administrativo de queja individual sobre posibles violaciones de derechos humanos dirigido conjuntamente contra todas las agencias implicadas ${ }^{124}$. Este mecanismo podría resultar más asequible a las personas en situación de gran vulnerabilidad que llegan a dichos puntos, cuyo acceso al TJUE, por más que sea posible teóricamente, resulta muy alejado de sus posibilidades en la práctica.

121 Resolución del Parlamento Europeo, de 2 de diciembre de 2015, sobre el Informe especial del Defensor del Pueblo Europeo relativo a su investigación de oficio OI/5/2012/ BEH-MHZ sobre FRONTEX, párr. C.

122 Sobre esta cuestión, véase CARRERA, DEN HERTOG, PARKIN, op. cit., supra nota 102.

123 Sobre esta problemática, véase F. CASOLARI, «The EU's Hotspot Approach to Managing the Migration Crisis: A blind Spot for International Responsability?», The Italian Yearbook for International Law Online, vol. 25, núm. 1, 2016, pp. 109-134.

${ }^{124}$ FERNÁNDEZ ROJO, op. cit., supra nota 73. 
En definitiva, se puede afirmar que el control jurisdiccional sobre los actos de las agencias va ganando terreno, aunque subsisten todavía numerosas zonas grises en relación a su alcance.

\section{CONSIDERACIONES FINALES}

El mapa de las agencias del ELSJ se encuentra inmerso en un proceso de cambios que ha aportado ya novedades notables y que dista mucho de estar cerrado. En el plano jurídico, dicho proceso ha venido impulsado tanto por la reforma de Lisboa como por la adopción de un Planteamiento Común para las agencias descentralizadas que establece criterios para una mayor sistemática y homogeneidad entre las agencias europeas. El examen de dicho proceso de reformas evidencia tres tendencias que merecen ser destacadas.

En primer lugar, una tendencia a ampliar el mapa de las agencias del ELSJ. Por un lado, desde la entrada en vigor del Tratado de Lisboa se han creado dos nuevas agencias, EASO y EULISA, que se añaden a las que ya tradicionalmente operaban en este campo, FRONTEX, CEPOL, EUROPOL y EUROJUST. Esta profusión de agencias puede explicarse teniendo en cuenta que el ELSJ incluye ámbitos materiales muy diferentes (asilo, inmigración, control de fronteras, cooperación judicial civil, cooperación judicial y policial penal) que exigen respuestas institucionales también diversas. Por otro lado, el desarrollo y el impulso a los objetivos del ELSJ han llevado a asociar a este ámbito agencias que no actúan únicamente en este terreno como la FRA, el EIGE o el OEDT. Así pues, la selección de las agencias que integran este mapa no puede establecerse con criterios únicamente formales en función de la base jurídica que ha originado su creación, lo cual daría un resultado limitado que no se corresponde con la realidad, sino que debe basarse en un criterio material que valore la contribución que las agencias aportan a los objetivos del ELSJ. La práctica institucional busca potenciar las sinergias, la transversalidad y la cooperación entre los diversos organismos de la UE. Atendiendo a dicha práctica, son nueve las agencias que actualmente integran el mapa del ELSJ, pero está ya acentuándose la vinculación a dicho ámbito de otras agencias, como, por ejemplo, la Agencia de la Seguridad Marítima en relación con las actividades de control de las fronteras marítimas o la Agencia de Seguridad de las Redes de la Unión Europea en la lucha contra los ciberdelitos, de tal manera que, en un futuro no muy lejano, el número de agencias del ELSJ es posible que deba ampliarse.

En segundo lugar, las últimas reformas de las agencias del ELSJ con funciones de cooperación operativa (FRONTEX, EUROPOL, y las propuestas que están aún sobre la mesa del legislador para un nuevo EUROJUST y una 
nueva EASO) refuerzan sus capacidades de actuación de forma notable. Se les reconoce un mayor protagonismo en la organización e impulso de operaciones conjuntas, se perfilan mejor las obligaciones de los Estados de suministrarles medios y datos, se les otorgan poderes de definición de estándares, y las consecuencias de sus evaluaciones sobre los riesgos y sobre la situación en los Estados son cada vez más concretas. Destaca, en particular, su refuerzo en el campo de la inteligencia y el procesamiento de datos. En definitiva, se avanza hacia un modelo de agencia que va más allá de la mera coordinación de acciones estatales, aunque sin convertirlas en agencias plenamente ejecutivas. A pesar de que las reticencias de los Estados a ceder competencias en ámbitos tan sensibles como el control de las fronteras o la actuación policial siguen muy presentes y operan como freno a una mayor atribución de poderes a las agencias, se puede argumentar que los cambios en el mapa de las agencias del ELSJ confirman su potencial transformador e integrador.

En tercer lugar, se constata una tendencia a homogeneizar la estructura de dichas agencias. Tanto la desaparición del tercer pilar tras la reforma de Lisboa como la adopción del Planteamiento Común para las agencias descentralizadas han sido claves al respecto. La Comisión ha afianzado su participación en los consejos de administración de las agencias del ELSJ y el procedimiento para la elección de su director se ha estandarizado, lo que refleja un equilibrio de poderes entre las instituciones europeas (Comisión y PE) en una primera fase de selección y consulta, y los Estados miembros, que intervienen en la decisión final en tanto que miembros del consejo de administración de la agencia. Sin embargo, a pesar de las reformas, las agencias de la cooperación policial y judicial que tuvieron su origen en el antiguo tercer pilar siguen reflejando un equilibrio institucional en el que el Consejo y los Estados miembros mantienen un mayor protagonismo.

Por último, es preciso constatar que tanto los Tratados como su aplicación por parte del legislador muestran una voluntad clara de intensificar el control democrático de dichas agencias, lo que fortalece el papel del PE. Su intervención se concreta tanto ex ante - en la medida en que interviene en el diseño de las agencias como colegislador - como ex post - mediante mecanismos específicos de rendición de cuentas en los que en algunos casos participan también los parlamentos nacionales, lo que constituye una destacable novedad- L La profundización en el control de las agencias no solo se ha materializado en el ámbito político, sino también en el jurisdiccional. El TJUE podrá enjuiciar la actividad de las agencias por la vía del recurso por responsabilidad extracontractual y por la vía del recurso de anulación. La previsión en algunas agencias de procedimientos administrativos de control específicos, ya sea en el campo de la protección de datos (EUROPOL) o del respeto de los derechos humanos (FRONTEX), abre la puerta a un recurso jurisdiccional sobre las 
decisiones tomadas en virtud de ellos, en la medida en que pueden afectar directamente a derechos de los ciudadanos.

En definitiva, el nuevo mapa de las agencias del ELSJ muestra la voluntad de legislador europeo y de los Estados miembros de otorgar para el desarrollo de los objetivos de la UE en este ámbito un protagonismo creciente a las agencias, que se han convertido en la cara más visible del ELSJ, dentro y fuera de la UE ${ }^{125}$. Las consecuencias del proceso de agencificación en este ámbito deben valorarse, a nuestro juicio, de manera positiva desde la perspectiva de la integración, puesto que hasta ahora la labor de las agencias ha puesto de manifiesto un gran potencial de europeización de sectores sensiblemente ligados a la soberanía estatal, lo que ha contribuido a crear una cultura de gestión conjunta y de coordinación entre las autoridades de los Estados, difundiendo estándares comunes y buenas prácticas y aportando medios eficaces para la consecución de los objetivos del ELSJ. Esta valoración positiva debe matizarse, sin embargo, para señalar, por un lado, que las potencialidades de lisbonización de las agencias no se han agotado totalmente $y$, por otro, que son aún muy mejorables los mecanismos de control necesarios para garantizar el pleno sometimiento de su labor al respeto de los derechos humanos y el equilibrio institucional de la UE.

${ }^{125}$ La expresiones de CARRERA, DEN HERTOG, PARKIN, op. cit., p. 337, supra nota 102. 
